ARTICLE

Received 17 May 2013 | Accepted 2 Aug 2013 | Published 5 Sep $2013 \quad$ DOI: 10.1038/ncomms3388

\title{
HuR and miR-1192 regulate myogenesis by modulating the translation of HMGB1 mRNA
}

Virginie Dormoy-Raclet ${ }^{1, \star}$, Anne Cammas ${ }^{1, \star}$, Barbara Celona ${ }^{2}$, Xian Jin Lian ${ }^{1}$, Kate van der Giessen ${ }^{1}$, Marija Zivojnovic ${ }^{1}$, Silvia Brunelli ${ }^{3,4}$, Francesca Riuzzi ${ }^{5}$, Guglielmo Sorci ${ }^{5}$, Brian T. Wilhelm ${ }^{6}$, Sergio Di Marco ${ }^{1}$, Rosario Donato ${ }^{5}$, Marco E. Bianchi ${ }^{2}$ \& Imed-Eddine Gallouzi ${ }^{1}$

Upon muscle injury, the high mobility group box 1 (HMGB1) protein is upregulated and secreted to initiate reparative responses. Here we show that HMGB1 controls myogenesis both in vitro and in vivo during development and after adult muscle injury. HMGB1 expression in muscle cells is regulated at the translational level: the miRNA miR-1192 inhibits HMGB1 translation and the RNA-binding protein HuR promotes it. HuR binds to a cis-element, HuR binding sites (HuRBS), located in the $3^{\prime} U T R$ of the HMGB1 transcript, and at the same time miR-1192 is recruited to an adjacent seed element. The binding of HuR to the HuRBS prevents the recruitment of Argonaute 2 (Ago2), overriding miR-1192-mediated translation inhibition. Depleting HuR reduces myoblast fusion and silencing miR-1192 re-establishes the fusion potential of HuR-depleted cells. We propose that HuR promotes the commitment of myoblasts to myogenesis by enhancing the translation of HMGB1 and suppressing the translation inhibition mediated by miR-1192.

\footnotetext{
${ }^{1}$ McGill University, Biochemistry Department, Goodman Cancer Center, 3655 Promenade Sir William Osler, Montreal, Quebec, Canada H3G 1Y6. ${ }^{2}$ San Raffaele University and Scientific Institute, Division of Genetics and Cell Biology, via Olgettina 58, 20132 Milano, Italy. ${ }^{3}$ Department of Health Sciences, University of Milan-Bicocca, 20090 Monza, Italy. ${ }^{4}$ San Raffaele Scientific Institute, Division of Regenerative Medicine, Stem Cells and Gene Therapy, via Olgettina 58, 20132 Milano, Italy. ${ }^{5}$ Department of Experimental Medicine and Biochemical Sciences, University of Perugia, Via del Giochetto 06122, Perugia, Italy. ${ }^{6}$ Institute for Research in Immunology and Cancer (IRIC), Université de Montréal, 2950 Chemin Polytechnique, Montreal, Quebec, Canada H3T 1J4.

* These authors equally contributed to this work. Correspondence and requests for materials should be addressed to I-E.G. (email: imed.gallouzi@mcgill.ca).
} 
T he process leading to muscle fibre formation during embryonic development, also known as myogenesis, involves the fusion of mononucleated myoblasts to form multinucleated myofibers ${ }^{1}$. Likewise, upon injury, adult muscle tissues are repaired by satellite cells, which are quiescent mononucleated cells that coexist with myofibers ${ }^{2}$. In response to injuries, satellite cells are activated; they first proliferate and then exit the cell cycle to fuse and form muscle fibre ${ }^{3-5}$. During both embryonic and injury-induced myogenesis, a cohort of intra- and extra-cellular factors act in concert.

HMGB1 (the high mobility group box 1) is a cytokine that is secreted by damaged muscle fibres and by infiltrating inflammatory cells after muscle injury. One of its main functions is to promote myogenesis by associating with the receptor for advanced glycation end products, which is expressed on the surface of myoblasts, resulting in the activation of a signal transduction cascade that induces the expression of promyogenic factors such as MyoD and myogenin ${ }^{6-12}$. It is also known that while HMGB1 is highly expressed in myoblasts or satellite cells, its level in muscle fibres is significantly reduced ${ }^{3,9}$. This suggests that maintaining a high expression level of HMGB1 during the early steps of myogenesis is required for the formation of functional myotubes. However, the mechanism controlling HMGB1 levels during myogenesis have never been investigated.

It has been shown that the $3^{\prime}$ untranslated region ( $3^{\prime}$ UTR) of HMGB1 messenger RNA (mRNA) is very long and contains elements that are uridyl-rich (U-rich) ${ }^{13}$. U-rich elements in the $3^{\prime} \mathrm{UTR}$ are known to modulate posttranscriptional events such as the cellular movement, the turnover and the translation of many mRNAs ${ }^{14,15}$. The expression of mRNAs encoding MyoD and myogenin is regulated posttranscriptionally. These mRNAs harbour AU-rich elements located in their $3^{\prime}$ UTRs that mediate their association with RNA-binding proteins such as HuR. This association is crucial for the stability and the expression of these messages during myogenesis ${ }^{6,17}$. As HuR binds to $M y o D$ and myogenin mRNAs only during the transition state from myoblasts to myotubes but not at earlier stages ${ }^{17}$, we concluded that $\mathrm{HuR}$ promotes myogenesis by stabilizing these mRNAs specifically at this later step during the myogenic process. However, knocking down the expression of $\mathrm{HuR}$ in undifferentiated muscle cells prevented their entry into the differentiation process ${ }^{17}$. Thus, HuR-dependent promyogenic activities could also involve modulating the expression of mRNA targets during the early steps of myogenesis.

In this study, we show that HMGB1 is required for myogenesis and that its expression in muscle cells is controlled at the translational level. Both miR-1192 and HuR associate with a U-rich element in the $3^{\prime}$ UTR of the HMGB1 mRNA. miR-1192 inhibits HMGB1 translation, but HuR promotes the translation of HMGB1 mRNA by preventing the formation of Argonaute 2 (Ago2)/miR-1192 complex. We propose that HuR promotes the commitment of myoblasts to myogenesis by enhancing the translation of HMGB1 and suppressing the translation inhibition mediated by miR-1192.

\section{Results}

The HuR-mediated expression of HMGB1 promotes myogenesis. HuR modulates the expression of MyoD and myogenin mRNAs in an ARE-dependent manner during the transition state from myoblasts to myotubes, but not at the earlier stages ${ }^{16-18}$. To identify potential HuR mRNA targets during the early steps of myogenesis, we performed an immunoprecipitation (IP) experiment combined with cDNA microarray analysis on total extracts from undifferentiated $\mathrm{C} 2 \mathrm{C} 12$ cells, a well-established murine myogenic cell line ${ }^{19}$.
$\mathrm{C} 2 \mathrm{C} 12$ cell extracts were immunoprecipitated with an anti-HuR or -immunoglobulin $\mathrm{G}$ ( $\mathrm{IgG}$ ) antibody. The RNAs associated with HuR were isolated and hybridized to mouse arrays. We revealed that HuR bound to 64 mRNAs in undifferentiated myoblasts (Supplementary Table S1). Among these messages, HMGB1 and the $\beta$-actin mRNAs are known to encode proteins that directly affect muscle cell differentiation ${ }^{9,10,20}$. As HuR associates with $M y o D$ and myogenin mRNAs only at later stages of the myogenic process $^{17,21}$, these messages were not on this list. While $\beta$-actin mRNA expression is known to depend on $\mathrm{HuR}^{22}$, nothing is known regarding the link between HMGB1 expression, its promyogenic function and $\mathrm{HuR}$ protein. Using IP coupled with quantitative (q) reverse transcriptase-PCR (RT-qPCR), we validated the association between HuR and HMGB1 mRNA in these cells (Supplementary Fig. S1a,b). Therefore, it is possible that HuR regulates HMGB1 expression during the early steps of myogenesis.

Several studies have suggested that the high expression level of HMGB1 in myoblasts is important for myogenesis, 3 . Indeed, we observed that while HMGB1 mRNA and protein are highly expressed during the early steps of muscle cell differentiation, their expression decreases at later steps (Supplementary Fig. S2). Despite this, the role of HMGB1 in the commitment of muscle cells to myogenesis is still elusive. To address this question, we depleted the expression of HMGB1 or HuR in C2C12 cells and the efficiency of myogenesis was determined by assessing cell morphology by phase contrast, the expression of the Myosin heavy chain (My-HC) by immunofluorescence (IF), and by determining the fusion index ${ }^{17}$ (Fig. 1a-e). We observed that HMGB1 depletion reduced the efficiency of muscle fibre formation by $>85 \%$ (Fig. 1c-e). As expected ${ }^{17}$, a similar reduction in myogenesis was also observed in $\mathrm{C} 2 \mathrm{C} 12$ depleted of HuR. Western blot analysis showed that the levels of My-HC and to a lesser extent myoglobin were reduced due to the knockdown of HMGB1 or HuR (Fig. 1f). Interestingly, exposing C2C12 cells depleted of endogenous HMGB1 to $400 \mathrm{nM}$ of recombinant HMGB1 (rHMGB1) re-established their ability to enter the myogenic process (Supplementary Fig. S2c,d). These observations demonstrate that HMGB1 promotes the early steps of myogenesis via its extracellular association with the receptor for advanced glycation end products.

Next, we assessed the impact of HMGB1 on muscle development and growth in vivo using Hmgbl wild-type (wt) $(+/+),+I-$ and $-I-$ mice. During vertebrate embryogenesis, skeletal muscle in the limb develops from progenitor cells originating in the somites ${ }^{23}$. Mice where the Hmgbl gene has been deleted die perinatally ${ }^{24}$. To assess the role of HMGB1 in mouse myogenesis, we therefore crossed $\mathrm{Hmgb1}^{+/-}$mice with homozygous MLC1/3F-nlacZ transgenic mice (wt for $H m g b 1)^{25}$ and collected the embryos at E10.5. As expected, half of the embryos were $\mathrm{Hmgb1^{+1+ }}$, whereas the other half was $\mathrm{Hmgb1}^{+/-}$; all of them carried the MLC1/3F-nlacZ transgene and showed blue myonuclei when stained for X-gal (Fig. 2). We observed a significant reduction in the number of somites in $H m g b 1^{+/}$- embryos when compared with wt controls (Fig. 2a). We then collected explants from wt, $H m g b 1^{+1-}$ and $H m g b 1^{-I-}$ embryos (E9.5), cultured them for 4 days $^{26}$ and determined the differentiation efficiency of myoblasts. We observed that Hmgb1-I- and + / - myoblasts formed significantly fewer myotubes than wt myoblasts (Fig. 2b). We next analysed 1-yearold $H m g b 1^{+/-}$mice to score for any reduction in muscle mass and cellularity when compared with wt mice. $H m g b 1^{+l-}$ mice showed a significant reduction in both total body weight and the mass of the tibialis anterior (TA) muscle (Fig. 2c). The myofibers in the TA muscle of $H m g b 1^{+1-}$ mice had a smaller crosssectional area (XSA) than those of control mice (Fig. 2d,e). We 
a

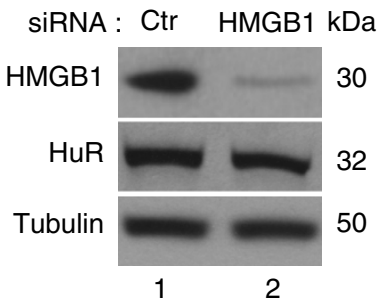

b

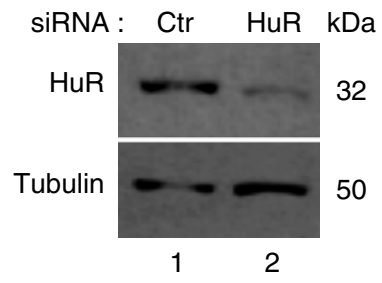

C

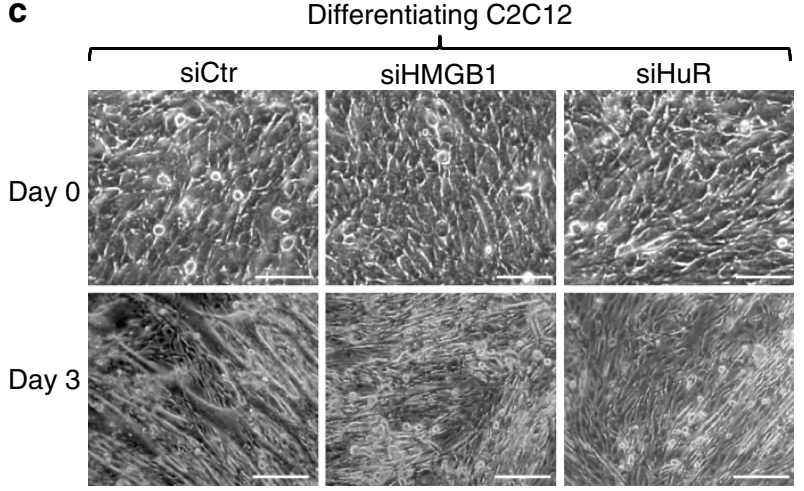

d

Day 3 of $\mathrm{C} 2 \mathrm{C} 12$ differentiation

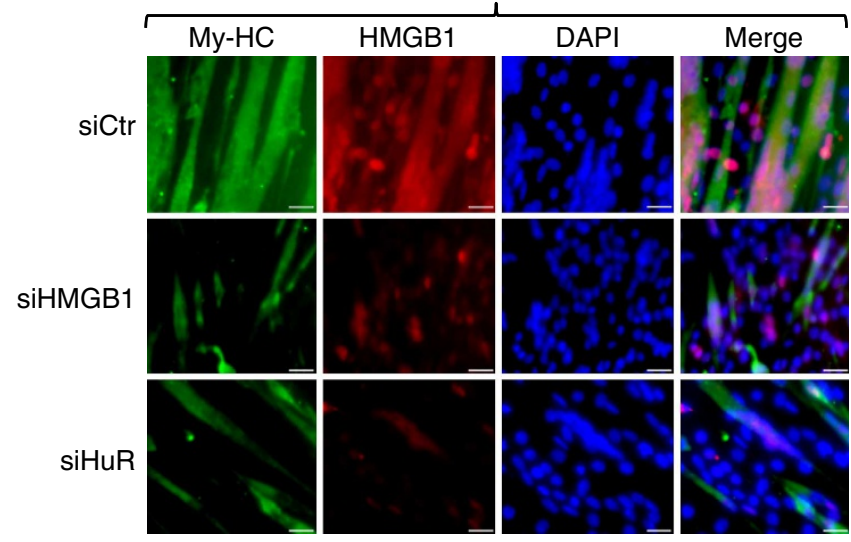

f

Day 3 of $\mathrm{C} 2 \mathrm{C} 12$ differentiation

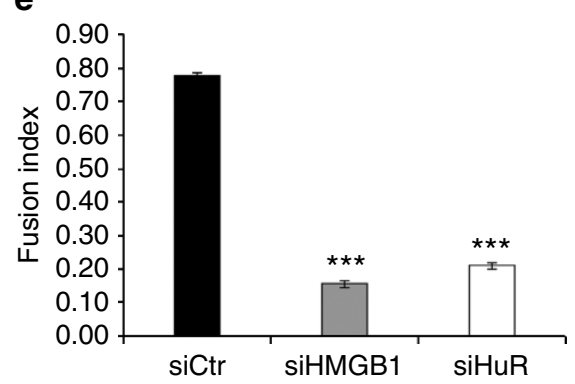

Figure 1 | Knocking down HMGB1 expression in myoblasts prevents their entry into the myogenic process. (a,b) HuR and HMGB1 knockdown were performed in $\mathrm{C} 2 \mathrm{C} 12$ cells and total cell lysates were prepared $48 \mathrm{~h}$ post-transfection. Western blotting was performed using antibodies against HMGB1, HuR and $\alpha$-tubulin as a loading control. (c) Phase contrast pictures showing the morphology of C2C12 cells transfected with control (siCtr), siHMGB1 or siHuR, at the time of differentiation induction (day 0) and at day 3. Scale bars, $50 \mu \mathrm{m}$ (d) IF with anti-My-HC, anti-HMGB1 antibodies and DAPI was performed to determine the differentiation status of the $\mathrm{C} 2 \mathrm{C} 12$ cells treated with the indicated siRNAs. Scale bars, $20 \mu \mathrm{m}$. Representative images from three independent experiments are shown. (e) The fusion index indicating the efficiency of $\mathrm{C} 2 \mathrm{C} 12$ differentiation was determined by calculating the number of nuclei in cells with more than 2 nuclei (myotubes) in relation to the total number of nuclei in each microscopic field. Data are presented as $+/-$ s.e.m. of three independent experiments. ${ }^{\star \star \star} P<0.0001$ ( $t$-test). (f) Total cell extracts were prepared at day 3 of differentiation. Western blotting was performed using antibodies against $\mathrm{My}-\mathrm{HC}$, myoglobin, and $\alpha$-tubulin as a loading control. Blots shown in a-b-f are representative of three independent experiments.

also confirmed that mouse embryonic fibroblasts and muscle tissue from $\mathrm{Hmgb1} 1^{+/}$mice express 50\% less HMGB1 than their $H m g b 1^{+/+}$counterparts (Fig. 2f). Additionally, a muscle injury experiment showed a marked delay in the $H m g b 1^{+/}-$mice in the regeneration process after injury as evidenced by the significant reduction in the XSA of regenerating fibres at both 7 and 14 days after injury (Fig. 3).

Together, these data demonstrate that maintaining a high expression level of HMGB1 in myoblasts is required for embryonal myogenesis and muscle regeneration after acute injury because of its release from myoblasts and/or damaged myofibers ${ }^{10,12,27}$.

HuR promotes the translation of the HMGB1 mRNA. The HuR protein is known to modulate the export, stability and/or the translation of its target mRNAs ${ }^{14,28}$. The fact that HuR has a key role during the early steps of myogenesis ${ }^{17}$ and associates with HMGB1 mRNA in muscle cells (Supplementary Fig. S1) suggested that $\mathrm{HuR}$ promotes muscle differentiation by regulating HMGB1 expression posttranscriptionally. Hence, we first determined whether HuR is required for the expression of HMGB1 in $\mathrm{C} 2 \mathrm{C} 12$ cells. We observed that knocking down HuR in myoblasts reduced the levels of the HMGB1 protein (by $>65 \%$ ), but not its three mRNA isoforms (Fig. 4a-d). Pulse-chase mRNA stability experiments $^{22}$, RNA fluorescence in situ hybridization ${ }^{29}$ and cellular fractionation indicated that HuR does not affect the cellular movement or the stability of HMGB1 messages (Supplementary Figs. S3 and 4). These observations therefore suggest that HuR regulates the translation of the HMGB1 mRNA. 
a
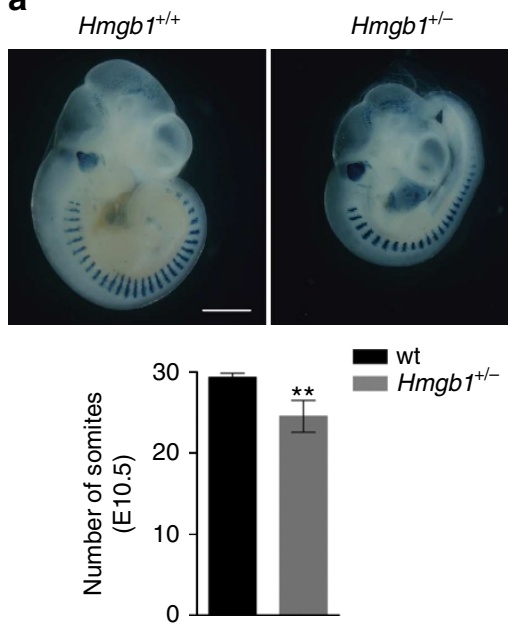

b
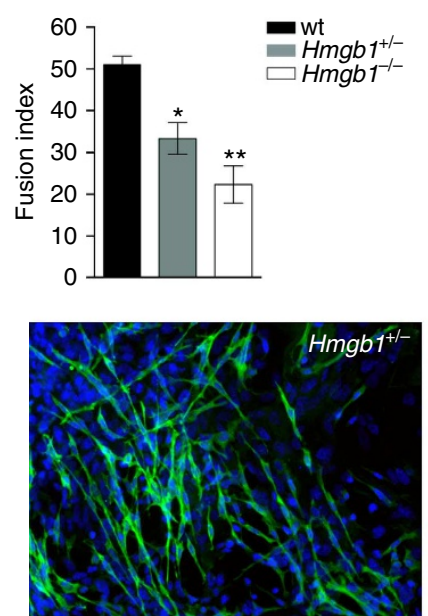
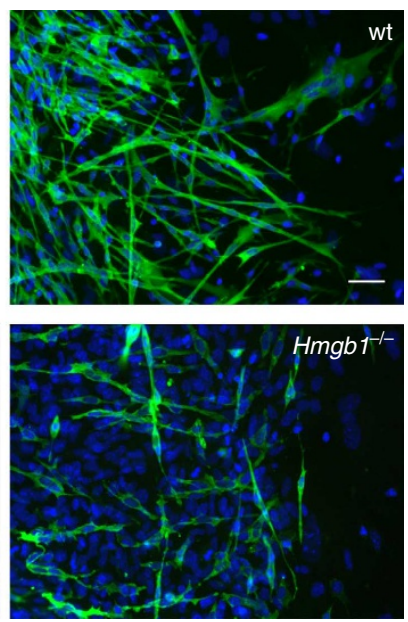

C
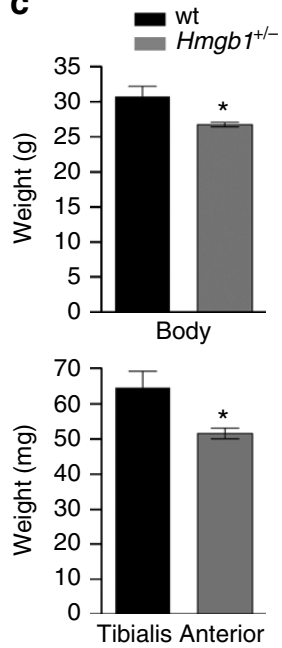

d

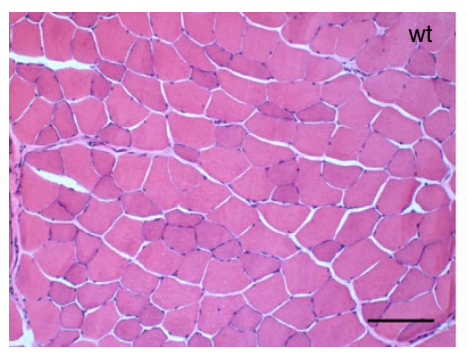

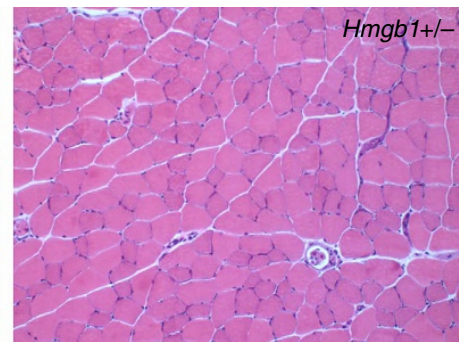
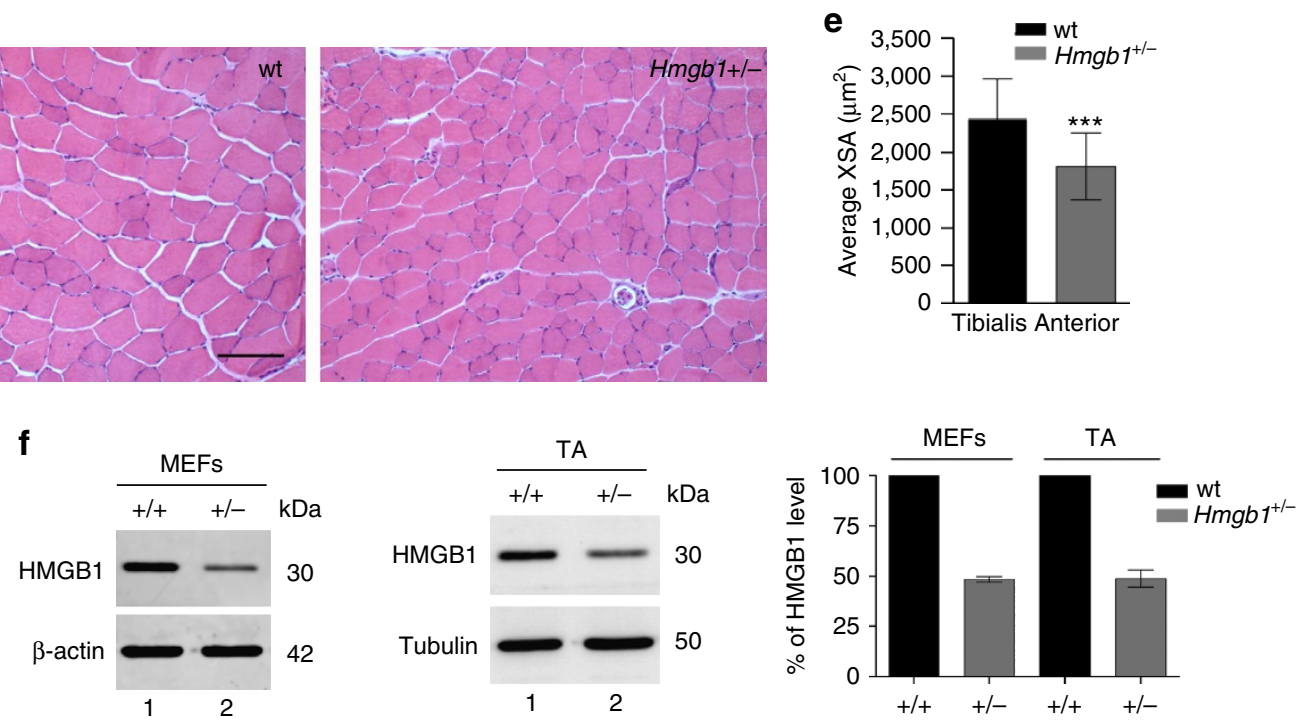

Figure 2 | HMGB1 is required for proper muscle fibre formation in vivo. (a) Top panel: whole-mount X-Gal staining of control heterozygote MLC1/3 F-nlacZ and double heterozygote MLC1/3 F-nlacZ-Hmgb1 +/ - embryos collected at E10.5. Scale Bars, 1 mm. Bottom panel: Histogram showing the average number of somites expressing MLC1/3 F-nlacZ in control and double heterozygotes embryos at E10.5. ${ }^{\star \star} P<0.01$ indicates a significant reduction in the number of transgene-expressing somites in $\mathrm{Hmgb1}+/-$ embryos compared with $\mathrm{Hmgb1}+/+$ (Data are presented as $+/-$ s.d., $t$-test, $n=6$ ). (b) PSM explants were derived from wt, Hmgb1 +/ - and Hmgb1 - / - embryos (E9.5), cultured for 4 days and analysed by IF with a specific antibody against My-HC (green) and DAPI counterstaining (blue). Scale bar, $20 \mu \mathrm{m}$. Fusion index was calculated as the number of nuclei in My-HC positive cells with more than 2 nuclei (myotubes) in relation to the total number of nuclei in each microscopic field. Data are presented as $+/-$ s.d. of three independent experiments. ${ }^{\star} P<0.05$ and ${ }^{\star}{ }^{\star} P<0.01$ ( $t$-test, $n=3$ ). (c) Body and TA weights of 1-year-old wt and Hmgb1+/ mice. Three animals were analysed per group. Error bars represent s.d. ${ }^{\star} P<0.05$ ( $t$-test). (d) Histology of TA muscle. Representative images of H\&E stained sections of TA muscles of 3-month-old wt and Hmgb1+/ - mice. Scale bar, $100 \mu \mathrm{m}$. (e) Mean cross-section area (XSA) of TA muscle fibres from 1-year-old wt and $\mathrm{Hmgb1}+/-$ mice. Error bars represent s.d. Nine hundred fibres were analysed for each group. ${ }^{\star \star \star} P<0.001$ versus wt (analysis of variance). (f) Western blots for HMGB1 were performed on equal amounts of total extracts from wt $(+/+)$ and heterozygous $(+/-)$ MEFs and adult TA. $\beta$-actin and tubulin are shown as loading controls. The blots shown are representative of three independent experiments. Western blot signals were quantified with ImageQuant software (GE Healthcare) and plotted $+/$ - s.d. from three independent experiments.

Sucrose fractionation experiments were performed to assess this possibility. We observed that while the depletion of HuR had no significant effect on the general distribution profile of polysomes (Fig. 4e), knocking down HuR resulted in a shift in the distribution of $H M G B 1$ mRNA towards lighter polysome fractions when compared with siCtr-treated cells. These results indicated that the HMGB1 transcript is less translated in the absence of HuR (Fig. 4f). As HuR-mediated effects on target mRNAs in muscle cells have been linked to its ability to accumulate in the cytoplasm $^{30}$, we tested whether this could also be the case for HMGB1 mRNA. To do this, we treated undifferentiated $\mathrm{C} 2 \mathrm{C} 12$ cells with the HuR cleavage product 1 (HuR-CP1), which promotes the cytoplasmic accumulation of $\mathrm{HuR}$ during myogenesis ${ }^{30}$. We observed that HuR-CP1 increased HuR level in the cytoplasm of muscle cells and promoted the expression of the HMGB1 protein (Fig. 4g,h). Taken together, these results show that HuR maintains the high expression level of HMGB1 in muscle cells by promoting the translation of HMGB1 mRNA. 

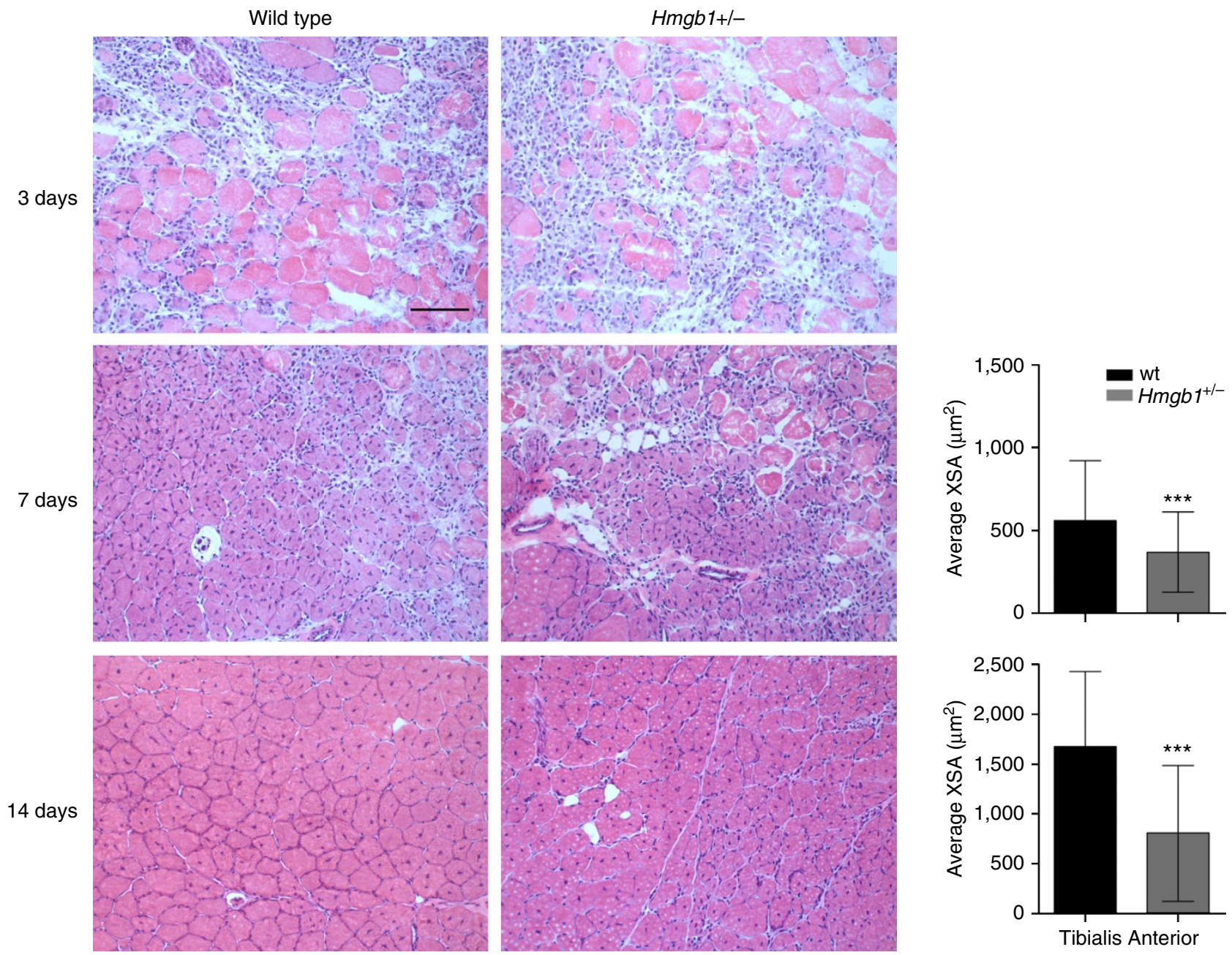

Figure 3 | HMGB1 is required for normal muscle regeneration after injury. Representative sections of TA muscles from wt and Hmgb1 $+/-$ mice stained with H\&E 3, 7 and 14 days after CTX injury. Scale bar, $100 \mu \mathrm{m}$. The cross-sectional area (XSA) of regenerating TA myofibers was decreased in $\mathrm{Hmgb1}+/-$ mice at both 7 and 14 days following injury. Nine hundred fibres were analysed for each group (three animals per group). Error bars in the histograms represent s.d. ${ }^{\star \star \star} P<0.001$ versus wt (analysis of variance).

HuR prevents miR-1192-mediated repression of HMGB1 translation. HuR affects the translation of target messages by associating with HuRBS located at either the $5^{\prime}$ or $3^{\prime} \mathrm{UTRs}^{14}$. Sequence analysis revealed the presence of a U-rich element in the $3^{\prime}$ UTR of the HMGB1 mRNA that is similar to a HuRBS in the $\beta$-actin $\mathrm{mRNA}^{22}$ (Fig. 5a). To assess whether this and/or other elements could mediate HuR binding, we performed RNA electromobility shift assays using total extracts from $\mathrm{C} 2 \mathrm{C} 12$ cells and thirteen radiolabelled cRNA probes that covered the entire $5^{\prime}$ and $3^{\prime}$ UTRs of HMGB1 mRNA (Fig. 5a). All the probes except P6 and P8 formed RNA-protein complexes when incubated with total cell extract (Fig. 5b). However, an anti-HuR antibody only shifted RNA-complexes (HuR-C) containing the P4 but not the other probes (Fig. 5b). A pull-down experiment confirmed the specificity of HuR binding: biotinylated P4 associated with HuR but not with CUGBP1, an RNA-binding protein known to modulate muscle differentiation ${ }^{31}$ (Supplementary Fig. S5a).

To delineate the HuRBS within P4, we divided this element into radiolabelled cRNA probes $\mathrm{P} 4-1,-2$ and -3 (Fig. 5c). A supershift containing the HuR-C was only generated with P4-1. A P4-1 mutant probe (mut-P4-1) in which every second $U$ in the U-rich element $\left(\mathrm{U}_{15}\right)$ was changed to a $\mathrm{C}$ (Fig. 5d) also failed to form a complex when incubated with extracts in the presence of the anti-HuR antibody. P4-HuR complexes were gradually competed away in the presence of an excess of unlabelled P-4 or P4-1 probes but not in the presence of an excess of unlabelled P4-3 or mut-P4-1 probes (Fig. 5e,f). These observations, together with the fact that recombinant GST-HuR but not GST alone was able to form an HuR-C (Supplementary Fig. S5b), demonstrate that the $U_{15}$ element located between nucleotides (nt) 1218 and 1233 comprises the HuRBS in the HMGB1-3'UTR.

Previous studies have indicated that HuR either competes or collaborates with miRNAs in order to regulate the translation of some of its mRNA targets 32,33 . We investigated whether this could also be the case for HMGB1 expression in muscle cells. As a first step, we identified miRNAs that associate with $\mathrm{HuR}$ in muscle cells. C2C12 cell extracts were immunoprecipitated with an anti-HuR antibody as described above and the miRNAs associated with HuR were isolated and identified using miRNA arrays (Exiqon, USA). We identified 20 miRNAs that were immunoprecipitated twofolds or more with the anti-HuR antibody when compared with the IgG control (Supplementary Table S2). Using the MSKCC (http://www.microrna.org/microrna/ releaseNotes.do), the BiBiSer (http://bibiserv.techfak.uni-biele feld.de/rnahybrid/) and the miRmap (http://mirmap.ezlab.org/ app/) websites, we identified that among these 20 HuR-miRNAs 
a

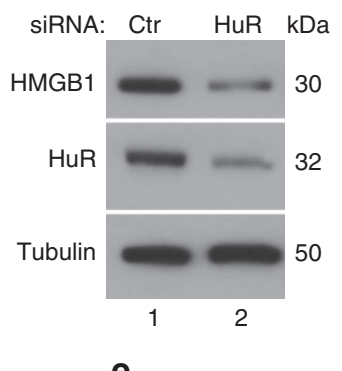

b

e
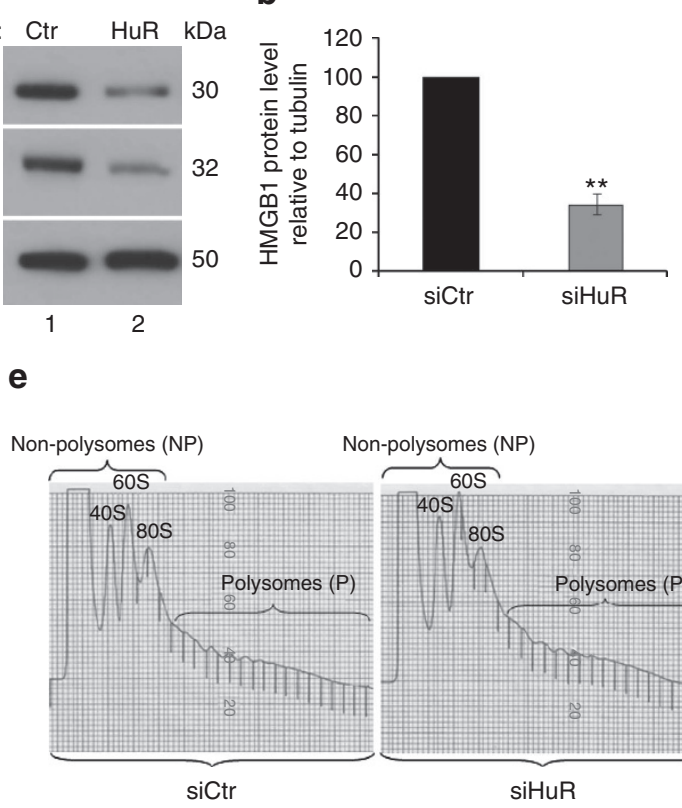

g
Non-polysomes (NP)

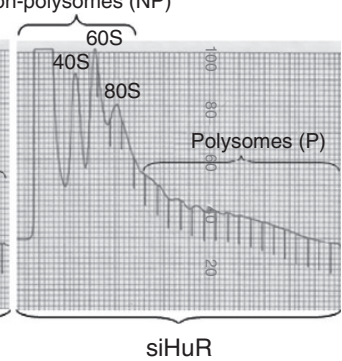

C

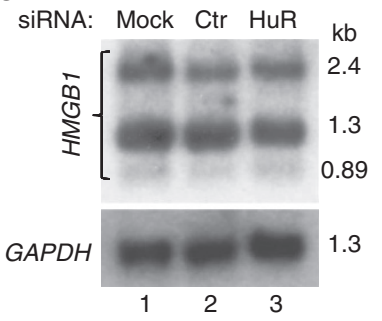

d

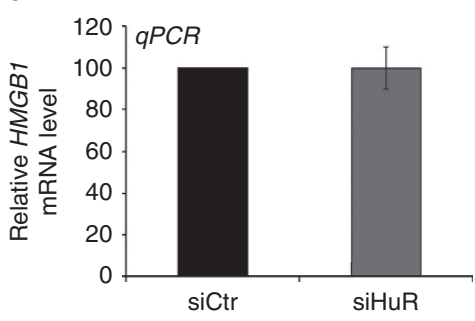

f
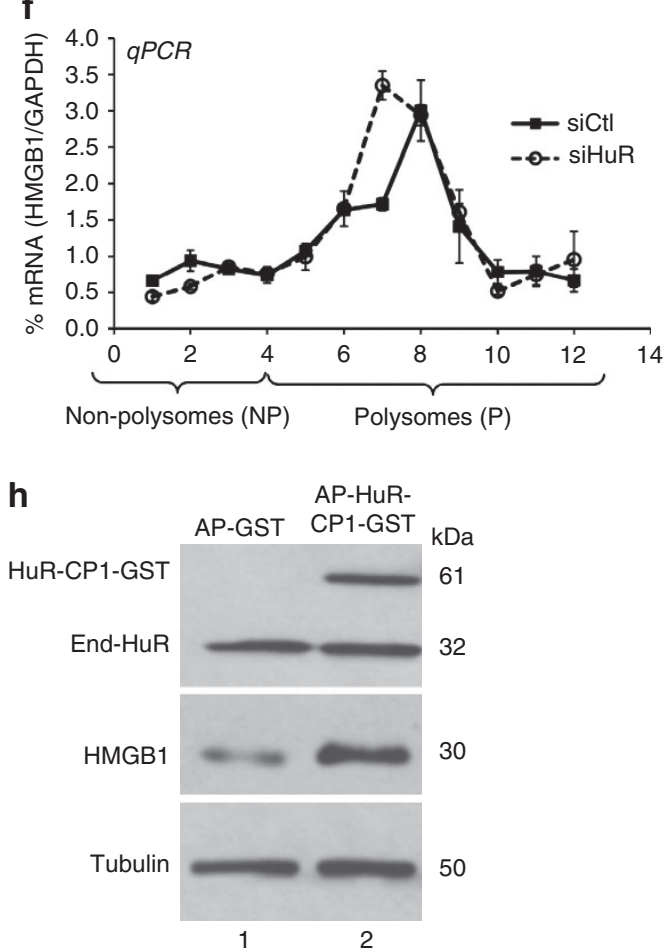

Figure 4 | HuR promotes the translation of HMGB1 in C2C12 cells. (a) Total extracts from C2C12 cells treated with siHuR or siCtr were used for western blots with antibodies against HMGB1, HuR and $\alpha$-tubulin as a loading control. (b) The HMGB1 protein level relative to $\alpha$-tubulin for each treatment was plotted as the percentage relative to siCtr-treated sample $+/-$ the s.e.m. of three independent experiments. ${ }^{\star \star} P<0.001$ ( $t$-test). (c) Northern blot of total RNA from $\mathrm{C} 2 \mathrm{C} 12$ cells treated with siHuR or siCtr. A representative blot of three independent experiments is shown. (d) Total RNAs from siHuR- or siCtr-treated C2C12 cells were subjected to RT-qPCR analysis using specific primers for HMGB1 and GAPDH mRNAs and plotted + / - the s.e.m from three independent experiments. (e) Sucrose gradient (15-50\%) polysome fractionation of extracts from exponentially growing C2C12 cells that were treated with siHuR or siCtr. The profile of polysome distribution did not differ between $\mathrm{C} 2 \mathrm{C} 12$ cells treated with siHuR or siCtr. (f) Quantitative RT-PCR was performed on the sucrose fractions using specific primers for HMGB1 and GAPDH mRNAs. Error bars represent s.e.m. from four independent experiments. ( $\mathbf{g}, \mathbf{h}) \mathrm{C} 2 \mathrm{C} 12$ cells were treated with HuR-CP1 as described ${ }^{30}$. The nuclear and cytoplasmic fractions (g) or total extracts (h) were prepared and used for western blot analysis with anti-HuR, -HMGB1 and $\alpha$-tubulin antibodies. All blots shown in $\mathbf{g}$ and $\mathbf{h}$ are representative of three independent experiments.

only miR-1192 is predicted to target the HMGB1 mRNA. miR1192 stood out, as the first seven Us (nt 1218-1225) of its 'seed' sequence (miRNA binding site, miRBS) are part of the U-rich element containing the HuRBS (Fig. 6a,b). Additionally, our screening (RT-qPCR and sequencing) indicated that miR-1192 is expressed in $\mathrm{C} 2 \mathrm{C} 12$ cells as well as in muscle and heart tissues, but not in the lung, spleen, MEFs or HeLa cells (Supplementary Fig. S6 and Supplementary Table S3). Therefore, it was possible that this miRNA could contribute to the modulation of HMGB1 expression in muscle cells.

We first determined the impact of the miRBS and HuRBS on the translation of a reporter mRNA containing the HMGB1 $3^{\prime}$ UTR. For these experiments, we used a Renilla luciferase ( $R$ Luc) reporter containing either a wt ( $\mathrm{R}$ Luc- $3^{\prime} \mathrm{HMGB} 1$ ) or a mutated $3^{\prime}$ UTR with mutations in the seed element of miR-1192
(R Luc-3'HMGB1-mut-miRBS), or the HuRBS ( $\mathrm{R}$ Luc$3^{\prime}$ HMGB1-mut-HuRBS) (Fig. 6c). Of note, as all the 15 Us of HuRBS were mutated in R Luc- $3^{\prime}$ HMGB1-mut-HuRBS, this reporter should be unable to recruit both HuR and miR-1192 to the HMGB1-3'UTR. We transfected each one of the constructs in $\mathrm{C} 2 \mathrm{C} 12$ cells depleted or not of $\mathrm{HuR}$ and measured luciferase activity $^{34}$ in comparison to the baseline activity of $\mathrm{R}$ Luc alone (Fig. 6d). In cells expressing endogenous HuR, the luciferase activity of R Luc-3'HMGB1 was $>60 \%$ higher than R Luc alone (Fig. 6d). Mutating the HuRBS (R Luc-3'HMGB1-mut-HuRBS) prevented this increase, confirming that the binding of HuR to the HMGB1-3'UTR actively promotes translation. Mutating the seed element of miR-1192 (R Luc-3'HMGB1-mut-miRBS), however, did not prevent the translation increase mediated by the HMGB1-3'UTR. Indeed, REMSA experiments demonstrated 
a

HMGB1 P4-1: GTT--- TTTT TTGTTTTgtt HtggTTTTTT TTTTTTTTTT ggc $\beta$-actin HuR-BS: $\quad$ GTTtggTTTT TTGTTTT--. -.-- TTTTTT TTTTTCTTTT ...

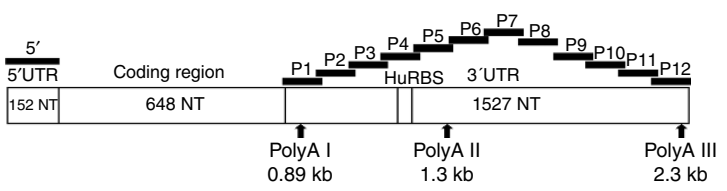

b

HMGB1-3'UTR

\begin{tabular}{|c|c|c|c|c|c|c|c|c|c|c|c|c|c|}
\hline & $\begin{array}{c}\text { HMGB1- } \\
\text { 5'UTR }\end{array}$ & P1 & P2 & P3 & P4 & P5 & P6 & P7 & P8 & P9 & P10 & P11 & P12 \\
\hline $\begin{array}{l}\text { TCE: } \\
\alpha \text {-HuR: }\end{array}$ & & $\begin{array}{l}-+ \\
--\end{array}$ & $\begin{array}{l}-++ \\
--+\end{array}$ & $\begin{array}{l}-+ \\
--\end{array}$ & $\begin{array}{l}-+ \\
--\end{array}$ & -- & & $\begin{array}{l}-+ \\
--\end{array}$ & $\begin{array}{l}-+ \\
--\end{array}$ & $\begin{array}{l}-+ \\
--\end{array}$ & $\begin{array}{l}-++ \\
--+\end{array}$ & $\begin{array}{l}-++ \\
--+\end{array}$ & $\begin{array}{l}-++ \\
--+\end{array}$ \\
\hline
\end{tabular}
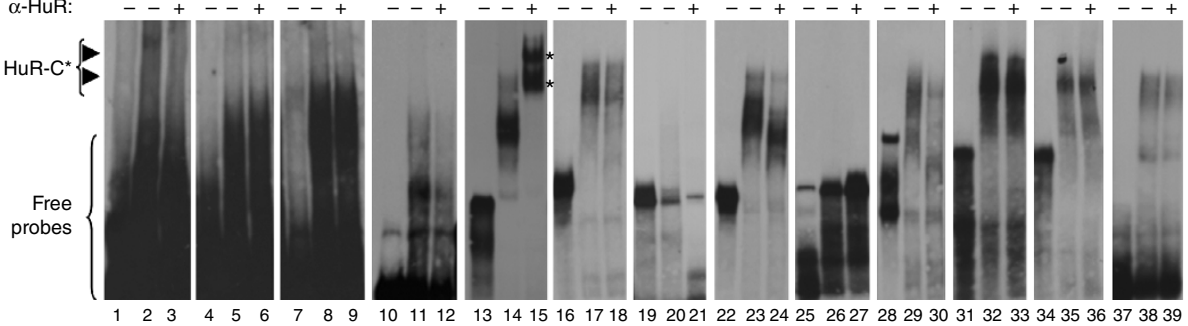

C

P4 $\left\{\begin{array}{l}\text { P4-1: GaCAGtAGTtTGGTTTTTTGTTTTTTTTTTTTTTTTCTTtT } \\ \text { P4-2: GGTTTTCTTTTTGGGTTTTATTTTTTTCATCTTC }\end{array}\right.$

P4-3: AGTTGTCTCTGATGCAGCTTATACGAAGATAA
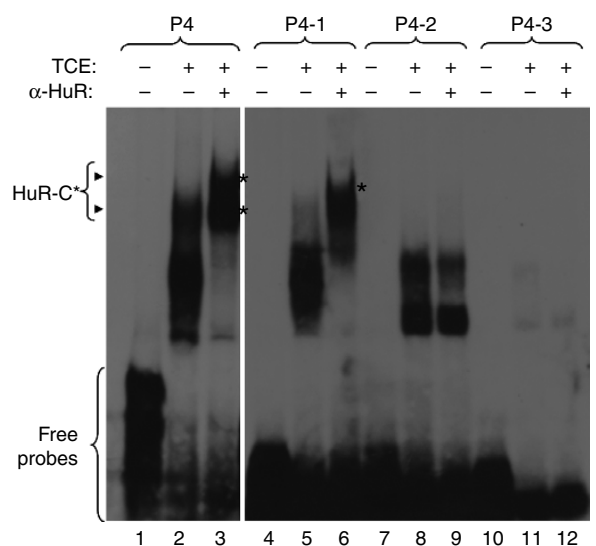

e

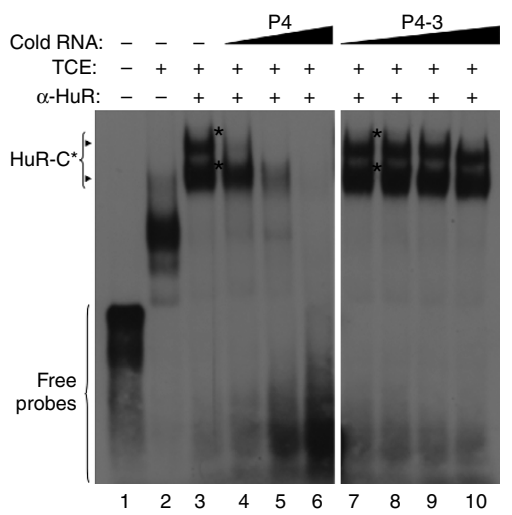

d

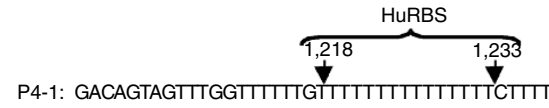
mut-P4-1: GACAGTAGTTGGTIIITGTCTCTCTCTCTCTCTCTII

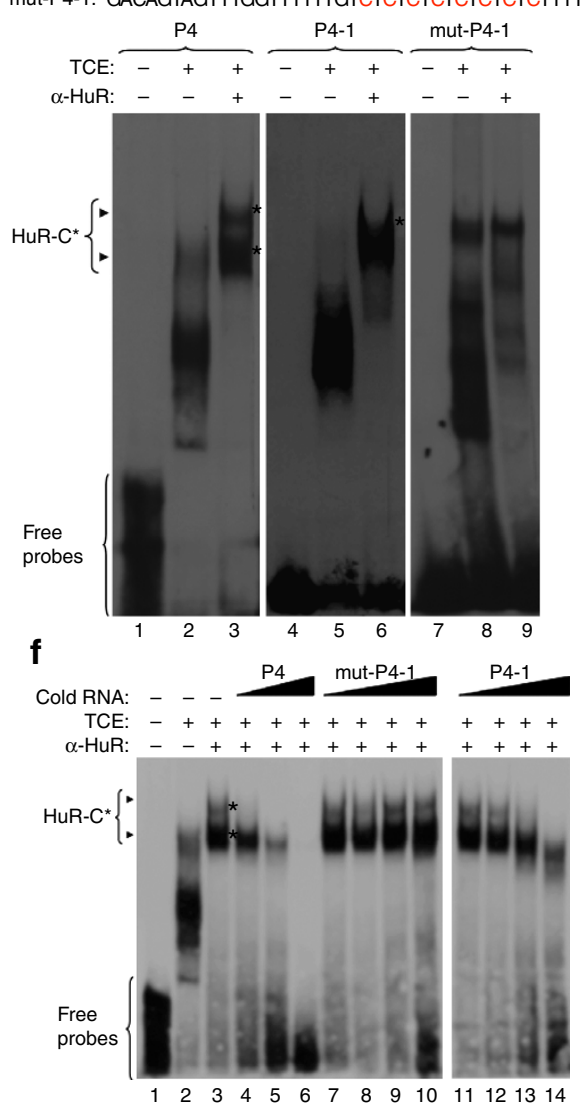

Figure 5 | HuR specifically binds to a U-rich element within the HMGB1 3'UTR. (a) Upper panel: alignment of the U-rich HuRBS within the HMGB1 and $\beta$-actin $3^{\prime}$ UTRs. Lower panel: schematic representation of the HMGB1 mRNA sequence. The elements covering the $5^{\prime}$ and the $3^{\prime}$ (P1-P12) UTRs of HMGB1 used to generate radiolabelled RNA probes for RNA electromobility shift assays are indicated. The accession number in the NCBI database of the HMGB1 mRNA sequence used to generate these probes is NM_010439. (b-f) Representative gels of supershifts carried out by incubating C2C12 TCE with radiolabelled cRNA probes and anti-HuR antibody. Supershifted complexes (HuR-C) contain HuR protein. (b) Gel-shift assay performed using radiolabelled 5'UTR and the 12 probes (P1 to P12) depicted in (a). (c) Nucleotide sequence of the probes P4-1, P4-2 and P4-3 that were generated to localize HuR binding site (upper panel). These probes were used for gel-shift assays (lower panel). (d) Nucleotide sequences of probe P4-1 (HuRBS) and mut-P4-1, showing the T->C changes in mut-P4-1 (upper panel). The arrowhead shows HuR-C (lower panel). (e,f) Gel-shift competition was performed with radiolabelled probe P4 and $1 \times, 10 \times$ and $100 \times$ excess of the indicated unlabelled probes. All blots shown in $\mathbf{b}-\mathbf{f}$ are representative of three independent experiments. 
that HuR can bind to the HuRBS despite mutations in miR-1192 seed element (Supplementary Fig. S7). These results clearly indicate that the recruitment of HuR to the HuRBS is sufficient to promote the translation of HMGB1 in muscle cells.

As the inhibition of HMGB1 translation occurs only in cells depleted of HuR (Fig. 4), we repeated the experiments described above in HuR-knockdown C2C12 cells. We observed that the R Luc-3'HMGB1 reporter, unlike the R Luc-3'HMGB1-mut-miRBS or R Luc-3'HMGB1-mut-HuRBS constructs, displayed $\sim 50 \%$ decrease in luciferase activity when compared with its control $\mathrm{R}$

a

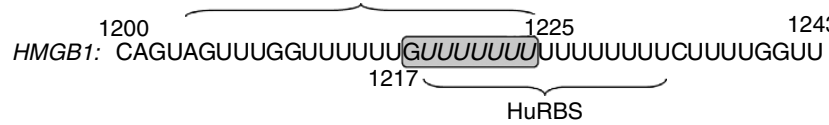

b

mmu-miR-1192/Hmgb1 alignment

3' UUAAACCAGACAAACAAACAAa 5' mmu-miR-1192

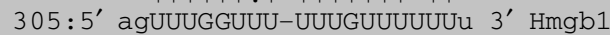

C
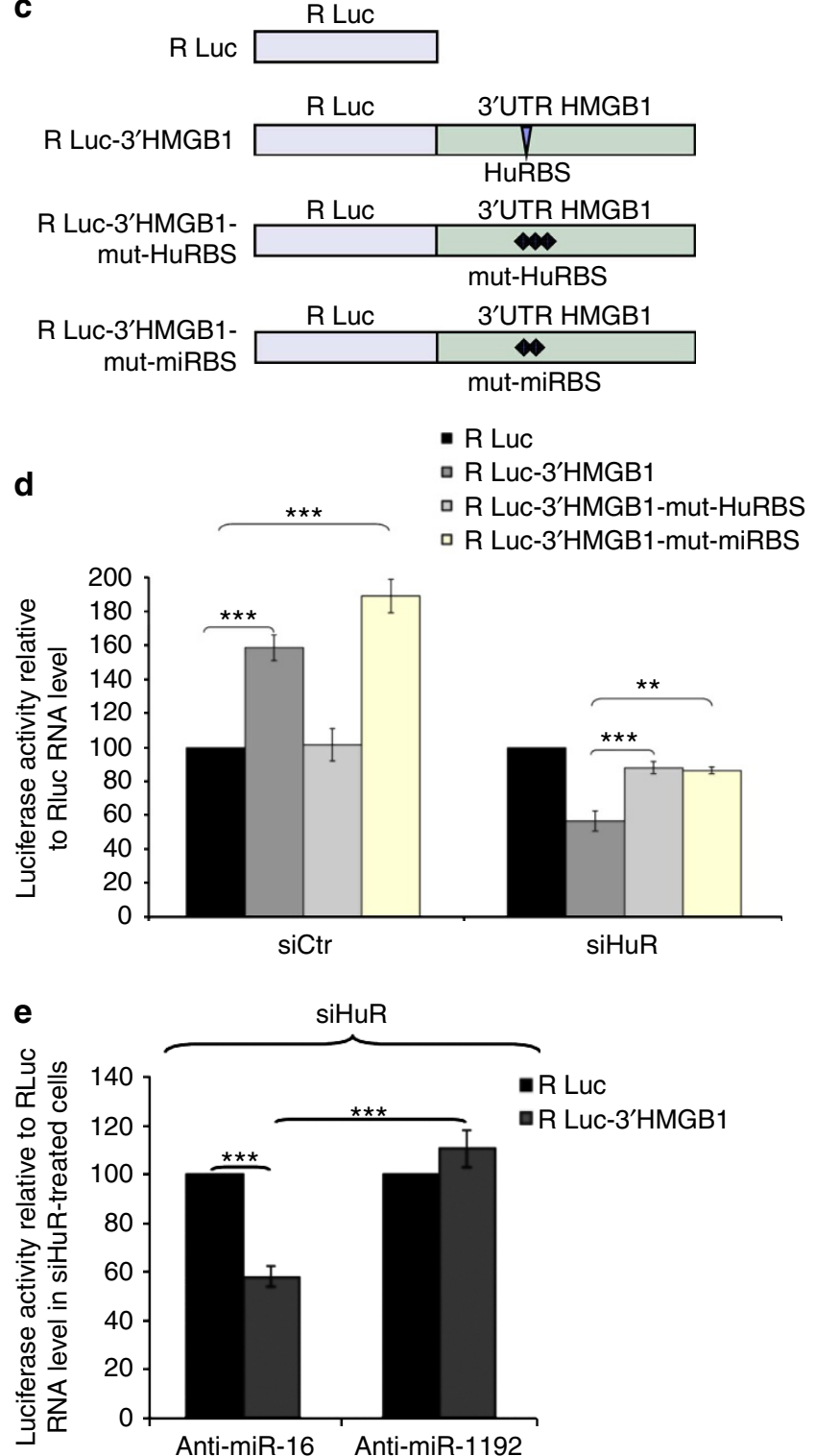

Luc counterpart (Fig. 6d). Additionally, silencing miR-1192 by a miRNA silencer (antagomir Anti-miR-1192) abrogated the decrease in the luciferase activity mediated by the HMGB1$3^{\prime}$ UTR. No such effect was, however, seen in cells treated with a control antagomir against miR-16 (Anti-miR-16) (Fig. 6e and Supplementary Fig. S8a). Importantly, the concentration of antagomir used in these experiments did not affect the viability of $\mathrm{C} 2 \mathrm{C} 12$ cells $^{35-37}$ and the steady state levels of endogenous HMGB1 mRNA (Supplementary Fig. S8b-d). We next generated mimics of miR-1192 with or without an A-to-C mutation in its

\section{f} Mimic Mutant miR-1192: 5' - AAACCAACAAACAGACCAAAUU - $3^{\prime}$

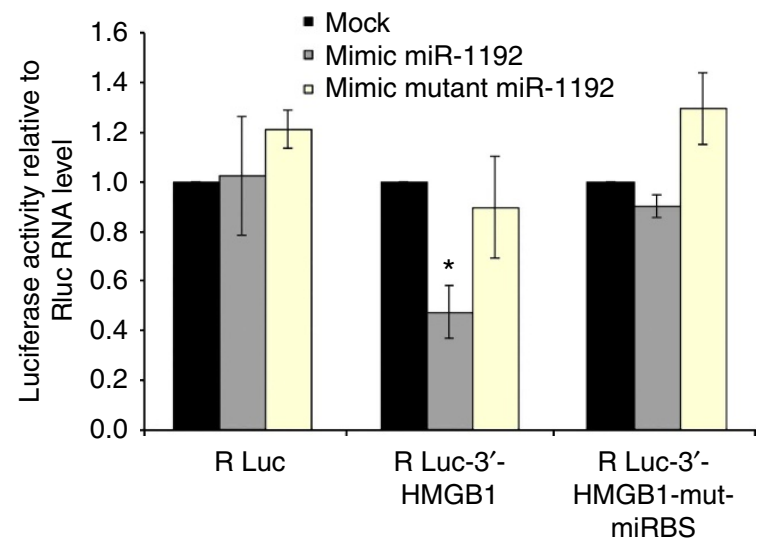

g

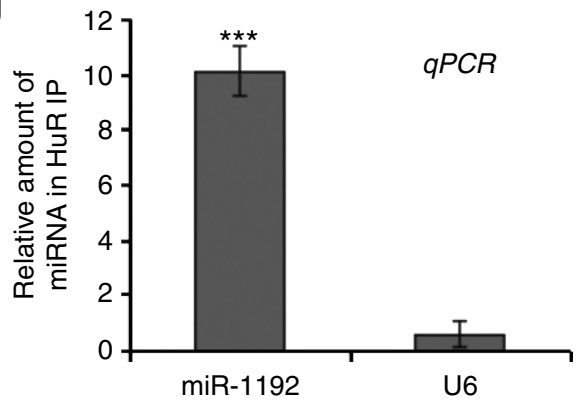

h

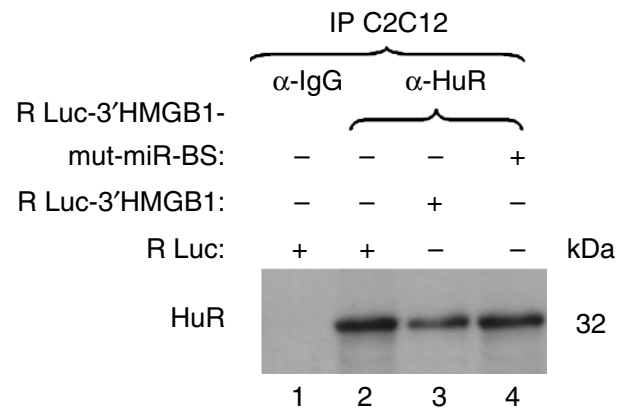

i

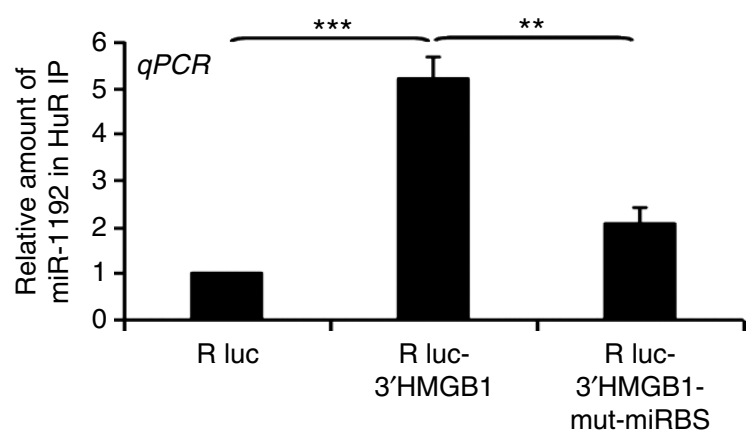


5th nucleotide (Fig. 6f). In HeLa cells, which do not express endogenous miR-1192 (Supplementary Fig. S6), the mimic miR1192 reduced the luciferase activity of $\mathrm{R}$ Luc- $3^{\prime} \mathrm{HMGB} 1$ by $\sim 50 \%$. The mutant miR-1192 mimic, however, had no effect on this activity (Fig. 6f). The luciferase activity of the R Luc$3^{\prime}$ HMGB1-mut-miRBS was not affected by the Mimic miR-1192, indicating that inhibition of R Luc- $3^{\prime}$ HMGB1 translation occurs via a direct binding to the miRBS. Collectively, these results demonstrate that in muscle cells, miR-1192 directly inhibits the translation of HMGB1 mRNA via the miRBS element, but this effect is overcome by the binding of HuR to its HuRBS.

Our IP combined to miRNA microarray data (Supplementary Table S2), which were validated by performing IP/RT-qPCR experiments (Fig. 6g) indicated that HuR and miR-1192 can coexist in the same complex in $\mathrm{C} 2 \mathrm{C} 12$ cells. To determine whether this complex is indeed assembled on the HMGB1-3'UTR, we performed the same IP/RT-qPCR experiment on C2C12 cells expressing either $R L u c$ alone, $R$ Luc- $3^{\prime} H M G B 1$ or the $R L u c$ $3^{\prime}$ HMGB1-mut-miRBS mRNAs. We observed that the level of miR-1192 in the HuR complex was fivefold greater in cells expressing the $R$ Luc- $3^{\prime} H M G B 1$ mRNA when compared with cells expressing mRNAs deficient in their ability to bind miR-1192 $(R$ Luc or R Luc-3'HMGB1-mut-miRBS) (Fig. 6h,i). Therefore, these observations clearly indicate that HuR and miR-1192 can bind simultaneously the $3^{\prime}$ UTR of HMGB1 mRNA. We next verified mechanistically how HuR could negate the ability of miR-1192 to repress the translation of the HMGB1 mRNA. miRNAs are known to translationally repress mRNAs via the recruitment of the Ago2, a component of the RNA-induced silencing complex (RISC) $^{38}$. We thus verified if HuR prevents the miR-1192mediated recruitment of Ago2 to the HMGB1-miRBS. Our data indicate that although both HuR and miR-1192 simultaneously bind to the HMGB1 mRNA $3^{\prime} \mathrm{UTR}$, the association of Ago2 to both miR-1192 and the HMGB1 mRNA is increased when HuR is depleted from C2C12 cells (Fig. 7). These experiments, therefore, indicate that $\mathrm{HuR}$ prevents the miR-1192-mediated translational repression of the $H M G B 1$ mRNA by interfering with the recruitment of Ago2.

Our data show that HMGB1 is one of the mRNA targets through which HuR promotes myogenesis. Specifically, the results outlined in Fig. 6 suggest that HuR-depleted muscle cells fail to enter myogenesis because in the absence of HuR, miR-1192 inhibits HMGB1 translation. Hence, silencing miR-1192 should rescue HMGB1 expression in HuR-depleted muscle cells and should also re-establish their myogenic potential. Our experiments showed that silencing miR-1192 but not miR-16 prevented the inhibition of HMGB1 translation in HuR-depleted C2C12 cells (Fig. 8a,b and Supplementary Fig. S9a). In the presence of endogenous HuR, however, Anti-miR-1192 had no effect on HMGB1 translation (Fig. 8a,b and Supplementary Fig. S9a). This result was further confirmed by the fact that while the depletion of HuR shifted the distribution of $H M G B 1$ mRNA towards lighter polysome fractions (Fig. 4f), silencing miR-1192 reversed this effect (Supplementary Fig. S9b). Next, we assessed whether the Anti-miR-1192-mediated rescue of HMGB1 translation is sufficient to promote the myogenic potential of HuR-knockdown cells. Indeed, silencing miR-1192 but not miR-16 re-established the myogenic potential of HuR-depleted cells (Fig. 8c,d) and the expression levels of My-HC, myoglobin and myogenin (Fig. 8e).

It was previously shown that miRNAs such as miR-519 and miR-16 inhibit HuR expression in various cell lines ${ }^{39-41}$. However, as HuR levels does not significantly change during the early steps of myogenesis in vitro ${ }^{16,17,42}$ and increase during muscle regeneration in vivo ${ }^{30}$ (Supplementary Fig. S10), miRNAmediated modulation of HuR expression in muscle cells seems to be ineffective in these conditions. Our experiments show that while the expression level of miR-16 increases during myogenesis both in vitro and in vivo (Supplementary Fig. S11a,b), it is the depletion but not the increased expression of miR-16 that modestly reduces the expression level of $\mathrm{HuR}$, with limited effects on HMGB1 as well as My-HC and myoglobin (Fig. 8e). In fact, a marked reduction of HMGB1 expression and the inhibition of myogenesis is observed only when HuR level is further reduced by small interfering RNA (Fig. 8e). These observations indicate that miR-1192 is active only when HuR level is below a critical threshold. All together, our data support a model whereby HuR helps undifferentiated muscle cells to enter myogenesis by supporting the translation of HMGB1 transcripts and preventing the action of Ago2/miR-1192 (Fig. 8f).

\section{Discussion}

In this study we show that HMGB1 is required for muscle fibre formation both in vitro and in vivo and uncover a novel mechanism by which muscle cells modulate HMGB1 expression. A general reduction in skeletal muscle tissues was previously observed in $H m g b 1^{-1-}$ mice, among several other defects ${ }^{24}$. Here we show that a precise level of HMGB1 expression is required for proper muscle fibre formation, as a $50 \%$ reduction in HMGB1 expression in embryos significantly decreases the efficiency of myogenesis. Thus, a tight control of HMGB1 expression levels appears essential for myogenesis.

More than a decade ago, it was discovered that HMGB1 mRNA harbours a long $3^{\prime}$ UTR with U-rich elements ${ }^{43-45}$ suggesting that

\footnotetext{
Figure 6 | HuR binding to a U8 element within HuRBS is sufficient to prevent the miR-1192-mediated inhibition of HMGB1 translation. (a) Schematic representation of the HuRBS and the seed element of miR-1192 (miR-1192 BS). (b) Diagram illustrating the bioinformatic approach used to predict miR-1192 as a putative miRNA targeting HMGB1 3'UTR. Shown here are complementarities of miR-1192 with HMGB1 3'UTR. (c) Schematic diagrams of luciferase constructs. (d-g) Effects of HuR, miRNAs, antagomirs and mimics. Error bars represent s.e.m of three independent experiments. ${ }^{\star \star \star} P<0.0001$, ${ }^{\star \star} P<0.001,{ }^{\star} P<0.05$ (Student's $t$-test). The amount of reporter RNA expressed in cells was determined by qPCR and used to normalize R Luc activities for each treatment. (d) Exponentially growing $\mathrm{C} 2 \mathrm{C} 12$ cells were treated with siCtr or siHuR and $24 \mathrm{~h}$ later luciferase constructs were introduced. Luciferase activity of R Luc construct was considered as 100\%. (e) miR-1192 and miR-16 antagomirs were transfected in siHuR-treated C2C12 cells previously transfected either with R luc alone or R luc-3'HMGB1. (f) Upper panel: schematic representation of the Mimic miR-1192 and Mimic mutant miR-1192. The asterisk $\left(^{*}\right)$ indicates the a-c mutation in the Mimic mutant miR-1192. Lower panel: HeLa cells were transfected with Mimic miR-1192 or Mimic mutant miR-1192 and 24 h later luciferase constructs were transfected. The luciferase activity of the mock-treated cells was set as reference. (g) Immunoprecipitation experiments were performed using a monoclonal HuR antibody, or IgG as a control, on total cell lysates from exponentially growing $\mathrm{C} 2 \mathrm{C} 12$ cells. RNA was isolated from the immunoprecipitate, and quantitative RT-PCR was performed using primers specific to miR-1192, miR-16 and U6 RNAs. The levels of miR-1192 and U6 RNAs in each IP were normalized against the level of miR-16. Error bars represent s.e.m of three independent experiments. $T$-test was used for statistical analysis. (h,i) Immunoprecipitation experiments were performed as in $(\mathbf{g})$ on total cell lysates from $\mathrm{C} 2 \mathrm{C} 12$ cells transfected with either $\mathrm{R}$ luc alone, R luc-3'HMGB1 or R luc-3'HMGB1-mut-miRBS. (h) Western blot was performed using an HuR antibody. This blot is a representation of three independent experiments. (i) The levels of miR-1192 in each IP were determined and are plotted with the s.e.m. of three independent experiments. ${ }^{\star \star \star} P<0.0001,{ }^{\star \star} P<0.001$ (Student's $t$-test).
} 


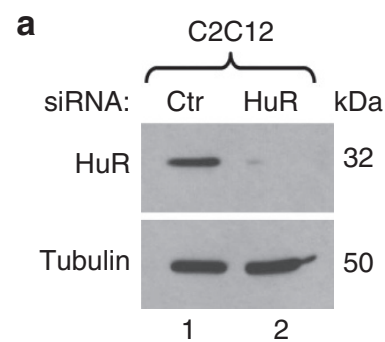

b
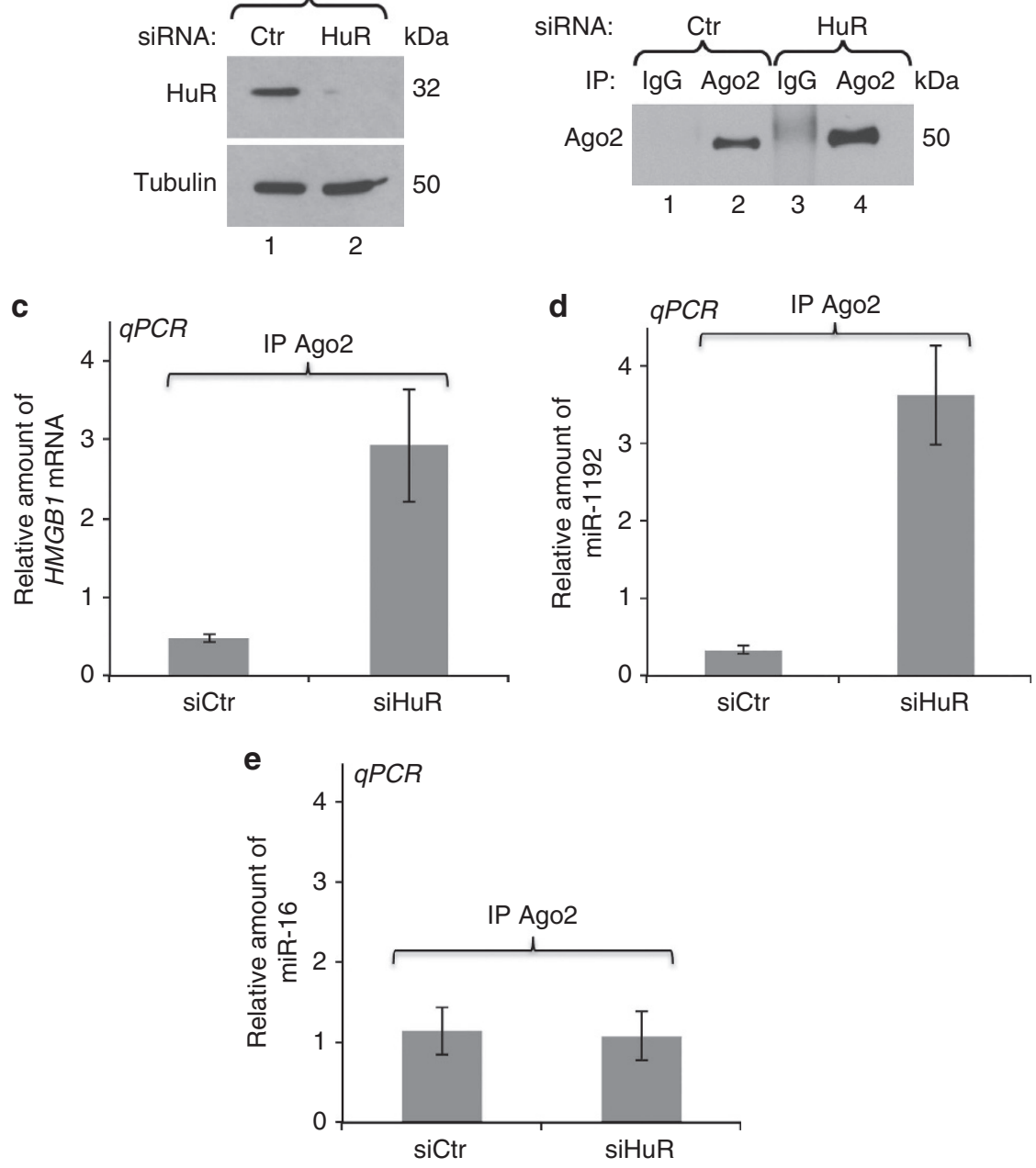

Figure 7 | HuR binding to the HuRBS prevents the recruitment of Ago2 to the HMGB1 mRNA. (a) Western blot analysis was performed using antibodies against $\mathrm{HuR}$ and $\alpha$-tubulin as a loading control on total cell extracts obtained from exponentially growing $\mathrm{C} 2 \mathrm{C} 12$ cells treated with a control (Ctr) or HuR specific (siHuR) siRNA. (b) Immunoprecipitation experiments were performed using a monoclonal Ago2 antibody, or anti-lgG antibody as a control, on the total cell lysates described in (a). The immunoprecipitation of Ago2 was then assessed by western blotting using an anti-Ago2 antibody. (c-e) RNA was isolated from the immunoprecipitate described above, and quantitative RT-PCR was performed using primers specific to (c) HMGB1 (d) miR-1192 (e) miR-16. The levels of HMGB1 mRNA, miR-1192 and miR-16 in each IP, relative to those in the IgG IP, were respectively normalized against the GAPDH mRNA and U6 levels. Error bars represent s.e.m of three independent experiments.

posttranscriptional events could regulate HMGB1 expression. Surprisingly, this possibility was never explored. Our data clearly establish that a posttranscriptional mechanism, via $\mathrm{HuR}$, has a key role in promoting HMGB1 expression in muscle cells. HuR, one of the well known posttranscriptional regulators, affects the expression of its target mRNAs by binding to specific U-rich elements in their $3^{\prime} \mathrm{UTR}^{14,15}$. We show that the $3^{\prime} \mathrm{UTR}$ of HMGB1 mRNA harbours such an element, the HuRBS, through which HuR promotes the translation of HMGB1 mRNA. In the absence of HuR, however, the microRNA miR-1192 is able to inhibit the expression of HMGB1. To our knowledge, this is the first report of the impact of a miRNA on HMGB1 expression. Incidentally, this is also the first report on the biological activity of miR-1192. Using several different techniques including miRNA microarray analysis, RT-qPCR with specific primers for miR-1192, and the sequencing of the PCR product that was generated by these primers, our data indicate that miR-1192 is expressed in muscle cells. Previous reports using RNA sequencing (RNA-seq), however, have failed to detect miR-1192 in the whole mouse embryo and muscle tissues ${ }^{46,47}$. As demonstrated by several recent studies ${ }^{48,49}$, technical biases during capture and preparation of the small RNA library has an impact on detection of small RNA molecules. Despite potential technical differences in methods used to precisely quantify the expression level of miR1192 in muscle cells, our data clearly show that this miRNA is expressed in muscle cells and is functionally relevant in modulating HMGB1 expression.

As HuR, HMGB1 and miR-1192 are highly expressed in muscle cells and during muscle regeneration ${ }^{30}$ (Supplementary Figs S10 and S11) and both HuR and miR-1192 can simultaneously associate with the $H M G B 1-3^{\prime} \mathrm{UTR}$, our data support a model whereby the binding of HuR to its HuRBS is sufficient to prevent miR-1192-mediated inhibition. Interestingly, the association of miR-1192 with Ago2, a key player in the RISC complex $^{38,50}$, is dramatically enhanced in muscle cells depleted of HuR. This suggests that HuR prevents the action of miR-1192 by interfering with the recruitment of Ago2 to the HMGB1 $3^{\prime}$ UTR. These data are consistent with previous observations showing that HuR promotes the translation of target messages by preventing the assembly of an active RISC complex on the Let-7 
a

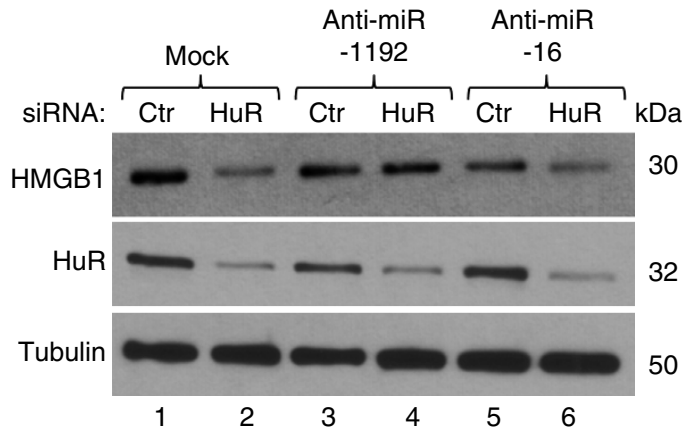

b

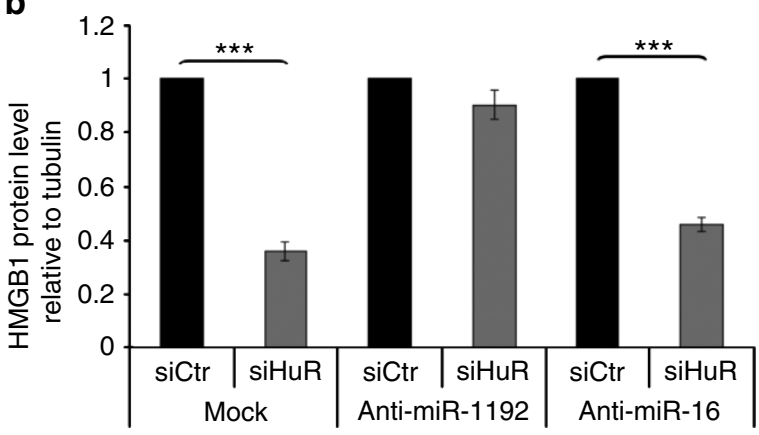

d

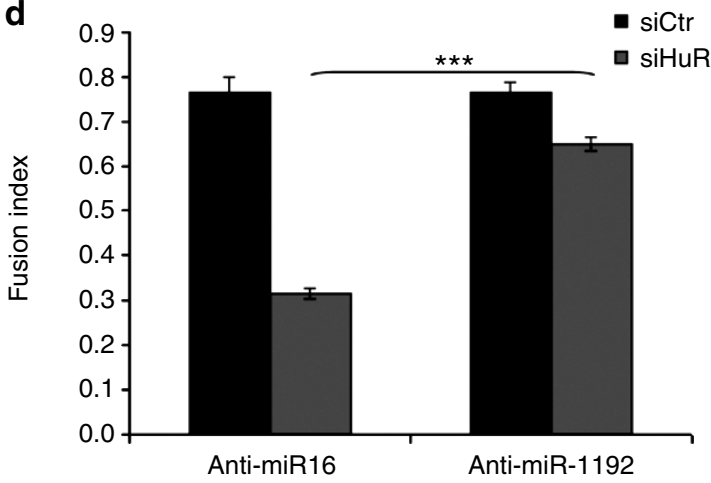

c
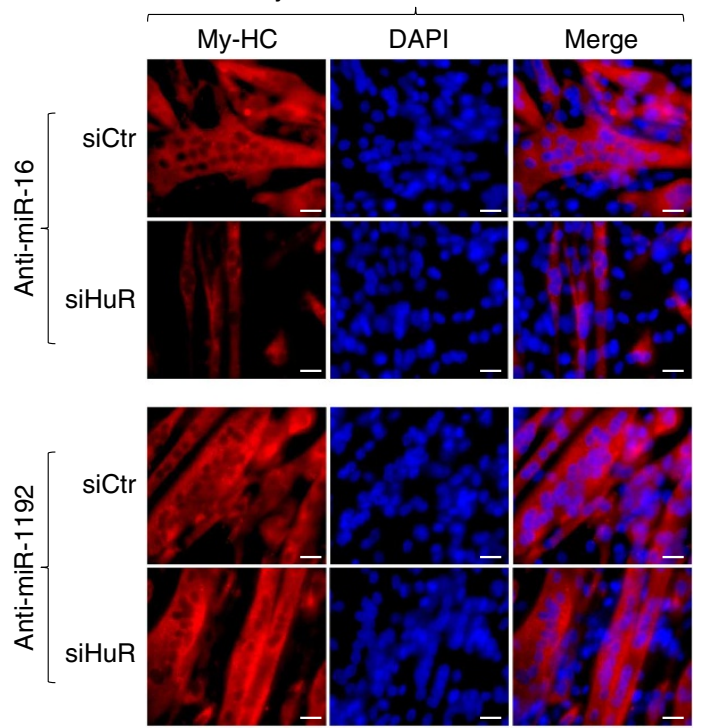

e

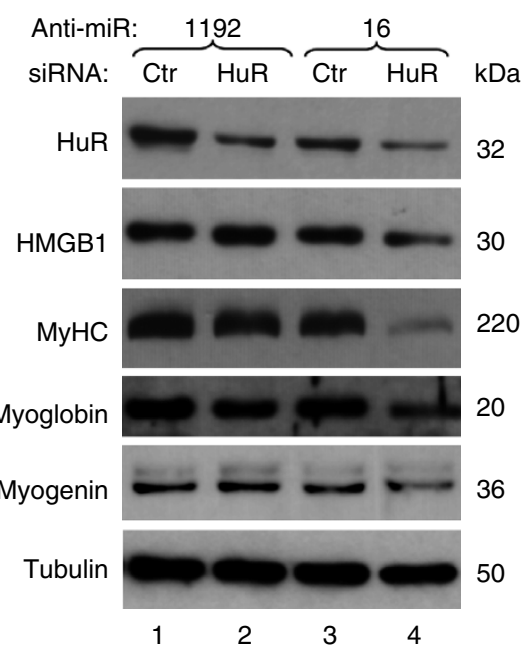

f

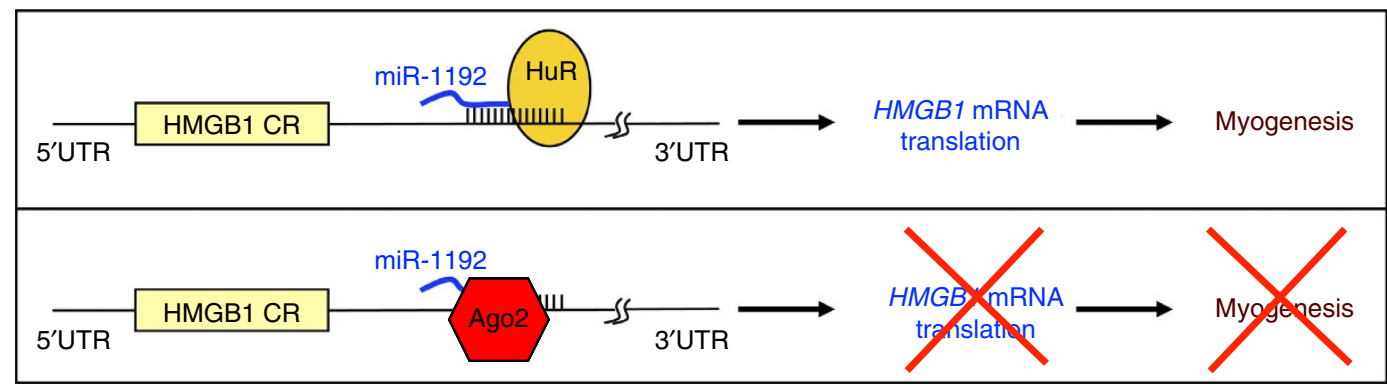

Figure 8 | Silencing miR-1192 reestablishes HMGB1 translation and rescues the myogenic potential of HuR-depleted muscle cells. (a) Exponentially growing $\mathrm{C} 2 \mathrm{C} 12$ were treated with siCtr or siHuR and were transfected $5 \mathrm{~h}$ later with antagomirs to miR-1192 or miR-16. Extracts from these cells were harvested and used for western blotting with anti-HMGB1, -HuR and - $\alpha$-tubulin antibodies. (b) The expression level of HMGB1 protein relative to $\alpha$-tubulin. Error bars represent s.e.m. of three independent experiments. ${ }^{\star \star \star} P<0.0001$ (student's $t$-test). (c) $\mathrm{C} 2 \mathrm{C} 12$ treated as in (a) were grown to confluency, induced to differentiate for three days and stained with anti-My-HC antibody and DAPI. Scale bars, $20 \mu \mathrm{m}$. The images shown are representative fields for each cell treatment from three independent experiments. (d) Fusion index of cells in (c). Error bars represent s.e.m. of three independent experiments. ${ }^{\star \star \star} P<0.0001$ (student's $t$-test). (e) Total extracts from cells treated as described above were blotted and probed with antibodies against HuR, HMGB1, My-HC, myoglobin, myogenin and $\alpha$-tubulin. A representative blot of two independent experiments is shown. (f) Schematic model illustrating how HuR promotes the myogenesis in undifferentiated muscle cells. HuR recognizes an $U_{8}$ element in the HMGBT-3'UTR adjacent to the seed element of miR-1192, and promotes HMGB1 translation and myogenesis. HuR mediates this effect even if miR-1192 is bound to its seed element (upper panel). In the absence of HuR, however, miR-1192 recruits Ago2 thus inhibiting HMGB1 translation and preventing myogenesis (lower panel). 
miRNA seed element ${ }^{51}$ even if its binding site is far away from the miRNA seed element. Therefore, these observations with our data suggest that HuR promotes the translation of target mRNAs by interfering with the formation of an active RISC complex regardless of the distance of its binding site from the seed element. This mechanism of action is different from the one described for the dead end 1 protein, another RBP, which promotes translation of the cyclin-kinase inhibitor $\mathrm{p} 27^{\mathrm{cip}}$ by preventing the recruitment of miR-221/222 to their seed elements ${ }^{52}$. Therefore, our findings not only add another example to the few studies on the cross talk between RNAbinding proteins and miRNAs, but also uncover a novel way by which cells, via proteins such as HuR, control miRNA-mediated effects. Our data demonstrate that via such a mechanism HuR induces the translation of HMGB1, which in turn promotes the entry of muscle cells into myogenesis.

By linking the interplay between HuR and miR-1192 to the translation modulation of HMGB1, we found a posttranscriptional mechanism that controls the expression of the main 'alarmin' in the organism ${ }^{53,54}$. HMGB1 is a damage-associated molecular pattern molecule that upon severe injury activates the innate immune system to recognize tissue damage and initiate reparative responses ${ }^{55,56}$. Typically, the increase in HMGB1 levels in stressed or activated inflammatory cells precedes the upregulation of HMGB1 transcript levels by several hours ${ }^{56}$. Our results suggest that posttranscriptional events might be responsible for this increase, as the HMGB1 mRNAs are both abundant ${ }^{43,44}$ and stable (Supplementary Fig. S2). Therefore, our study may open the door to new strategies to manipulate HMGB1 levels under various conditions. Such a strategy could help promote the beneficial effects of HMGB1 (for example, the activation of muscle regeneration and wound healing) while limiting/preventing the deleterious outcomes of its overproduction during life-threatening assaults (for example, ischaemia, burn, infection or sepsis).

\section{Methods}

Plasmid construction. The pCMV-SPORT6 plasmid containing the full-length HMGB1 cDNA (accession number: BC008565) was purchased from Open Biosystems (catalogue number: MMM1013-64094). pRL-luc-3'HMGB1-mut-miRBS was generated by Norclone Biotech Laboratories, Kingston, ON, Canada. The fulllength $3^{\prime}$ UTR of mouse HMGB1 was subcloned into a pRL-SV40 vector (Promega) by performing PCR amplification using the following primers: forward $5^{\prime}$-TTG GTT CTA GCG CAG TTT TT- $3^{\prime}$ and reverse $5^{\prime}$-TCA TCC AGG ACT CAT GTT CAG- $3^{\prime}$. The pRL-SV40 vector was digested by Xbal restriction enzyme (New England Biolabs), followed by a treatment with the T4 DNA polymerase, and then dephosphorylated. The PCR insert was ligated into the plasmid using the Quick Ligase enzyme (Promega) according to the manufacturer's instructions. pRL-luc$3^{\prime}$ HMGB1-mutHuRBS was generated using a specific primer containing the mutations and Quickchange site-directed mutagenesis kit (Stratagene). The MISSION short hairpin RNA (shRNA) plasmid (siHMGB1; Sigma-Aldrich) was used to knock down HMGB1. MISSION pLKO.1-puro vector encoding scrambled shRNA (siCtr; SHC001) was used as a control.

Cell culture and transfection. C2C12 muscle cells (ATCC) were grown in media containing 20\% fetal bovine serum (Invitrogen) in DMEM (Dulbecco's modified eagle medium from Invitrogen). In order to induce muscle cell differentiation, cells were switched to a media containing DMEM, $2 \%$ horse serum, penicillin/streptomycin antibiotics (Invitrogen), and $50 \mathrm{mM}$ HEPES, pH 7.4 (Invitrogen) when their confluency reached $100 \%$ (refs 17,42). $\mathrm{Hmgl}^{+/+}$and $\mathrm{Hmgb1}^{-1-}$ mouse embryonic fibroblasts (MEFs) (HMGBiotech, Milan, Italy) were cultured in DMEM supplemented with penicillin/streptomycin and $10 \%$ fetal bovine serum (Sigma-Aldrich). Transfections with small interfering RNAs specific for HuR or plasmids were performed using Lipofectamine and Plus reagents (Invitrogen) or jetPEI (Polyplus Transfection) according to the manufacturer's instructions. The same transfection protocol was used to treat C2C12 cells with $200 \mathrm{nM}$ miR-1192 or miR-16 antagomirs (Dharmacon).

HMGB1 rescue experiments. Transient transfection of $\mathrm{C} 2 \mathrm{C} 12$ cells was carried out using jetPEI (Polyplus Transfection), as recommended by the manufacturer. Briefly, C2C12 cells were transfected with the MISSION shRNA plasmid (Sigma-
Aldrich) to knock down HMGB1 or with the MISSION pLKO.1-puro vector encoding a scrambled shRNA (SHC001) as a control. Forty-eight hours posttransfection, the cells were switched to differentiation media and cultured for additional $48 \mathrm{~h}$ in the absence or presence of recombinant HMGB1 (400 nM).

Preparation of cell extracts and immunoblotting. Total cell extracts were prepared by incubating undifferentiated or differentiated C2C12 cells on ice for $15 \mathrm{~min}$ with lysis buffer $(50 \mathrm{mM}$ HEPES $\mathrm{pH} 7.0,150 \mathrm{mM} \mathrm{NaCl}, 10 \%$ glycerol, $1 \%$ Triton, $10 \mathrm{mM}$ pyrophosphate sodium, $100 \mathrm{mM} \mathrm{NaF}, 1 \mathrm{mM}$ EGTA, $1.5 \mathrm{mM} \mathrm{MgCl}_{2}$, $1 \times$ protease inhibitor (Roche), $0.1 \mathrm{M}$ orthovanadate, $0.2 \mathrm{M}$ PMSF), then centrifuge at $12,000 \mathrm{~g}$ at $4^{\circ} \mathrm{C}$ and the supernatant was kept ${ }^{17}$. The extracts were run on an SDS-PAGE and transferred to nitrocellulose membranes (Bio-Rad). The samples were analysed by western blotting ${ }^{57}$ with antibodies against $\operatorname{HuR}(3 \mathrm{~A} 2,1: 10,000)^{57}$, HMGB1 (Abcam,1:1,000), My-HC (MY32;Sigma,1:1,000), Myogenin (F5D, Developmental studies Hybridoma Bank, 1:250), $\alpha$-tubulin (Developmental studies Hybridoma Bank, 1:1,000), hnRNPA1 (Cell Signalling, 1:1,000) ${ }^{22}, \beta$-actin (Sigma,1:500), myoglobin (DAKO, 1:500) and Ago2 (Cell Signalling,1:1000). Full blots are provided in Supplementary Fig. S12.

Immunofluorescence. IF was performed using undifferentiated or differentiated $\mathrm{C} 2 \mathrm{C} 12$ cells that were grown to sub-confluency in DMEM (Dulbecco's modified eagle medium from Invitrogen ${ }^{17}$. After the appropriate experimental treatments, cells were rinsed twice in phosphate-buffered saline (PBS), fixed in 3\% phosphatebuffered paraformaldehyde (Sigma) and permeabilized in 0.5\% PBS-goat serum with Triton. After permeabilization, cells were incubated with primary antibodies against My-HC (MF-20, developmental studies Hybridoma Bank, 1:1,000), HuR $(3 \mathrm{~A} 2,1: 1,000)$ or HMGB1 (Abcam,1:1,000)) for $1 \mathrm{~h}$ at room temperature and then incubated with goat anti-mouse or anti-rabbit secondary antibodies conjugated with Rhodamine (red) or FITC (green) from Molecular Probes (Eugene, OR). To visualize the nucleus, cells were stained with DAPI (Molecular Probes). Microscopic analyses were performed using an AXIOVERT $200 \mathrm{M}$ (Zeiss).

ק-Galactosidase staining. MLC1/3F-nlacZ homozygous transgenic mice ${ }^{25}$ were mated with $H m g b 1^{+1-}$ heterozygotes. Pregnant females were killed by cervical dislocation at E10.5. Embryos were isolated in PBS, fixed for $2 \mathrm{~h}$ in $4 \%$ paraformaldehyde $\mathrm{pH} 7.4$ at $4^{\circ} \mathrm{C}$, washed in $\mathrm{PBS}$ for $20 \mathrm{~min}$ and equilibrated in $20 \%$ sucrose PBS. Fixed embryos were then stained for $1 \mathrm{~h}$ at $37^{\circ} \mathrm{C}$ in $1 \mathrm{mg} \mathrm{ml}^{-1}$ X-gal solution of PBS, also containing $5 \mathrm{mM} \mathrm{K}_{4} \mathrm{Fe}(\mathrm{CN})_{6}, 5 \mathrm{mM} \mathrm{K}{ }_{3} \mathrm{Fe}(\mathrm{CN})_{6}, 2 \mathrm{mM}$ $\mathrm{MgCl}_{2}, 0.2 \%$ NP-40 PBS. Hmgb1 ${ }^{+1}$ embryos were identified by PCR analysis of yolk sac DNA using the following primers: HMGB1for 5'-GCA GGC TTC GTT GTT TTC ATA CAG- $3^{\prime}$ and HMGB1rev $5^{\prime}$-TCA AAG AGT AAT ACT GCC ACC TTC-3' for the wt allele; NEOfor $5^{\prime}$-TGG TTT GCA GTG TTC TGC CTA GC-3' and NEOrev $5^{\prime}$-CCC AGT CAT AGC CGA ATA GCC-3' for the targeted allele. These animal studies were approved by the San Raffaele University Animal Care Committee.

Histology and morphometric analysis. TA muscles were dissected from 1-yearold wild-type and $\mathrm{Hmgbl}^{+I-}$ mice and frozen in liquid nitrogen-cooled isopentane. Serial sections ( $8 \mu \mathrm{m}$ thick) were stained with hematoxylin and eosin. Morphometric analyses were performed on sections of TA using ImageJ to determine the cross-sectional area of 900 fibres for each group.

Fusion index. Explants of presomitic mesoderm ${ }^{58}$ were dissected from wt, $\mathrm{Hmgb1} 1^{+1-}$ and $\mathrm{Hmgb1} 1^{-{ }_{-}}$embryos at E9.5, plated on collagen-coated dishes and cultured for 4 days in DMEM supplemented with $20 \%$ FCS and $50 \mu \mathrm{g} \mathrm{ml}^{-1}$ gentamycin. On day 4, cultures were processed for immunoflorescence with an antibody specific for My-HC (MF-20, Developmental Studies Hybridoma Bank, 1:20 dilution). Fusion index was determined as the number of nuclei in sarcomeric myosin-expressing cells with more than two nuclei versus the total number of nuclei.

Regeneration assay. Muscle injury was performed on the TA of 3-month-old wt and $H m g b 1+/-$ mice by injecting $50 \mu \mathrm{l}$ of $10 \mu \mathrm{M}$ CTX (three animals per group). Mice were killed 3, 7 or 14 days after CTX injection, and the TA muscles were dissected and frozen in liquid $\mathrm{N}_{2}$-cooled isopentane. Ten-micrometre serial muscle sections were stained with hematoxylin and eosin. Alternatively, injury of $\mathrm{C} 57 \mathrm{BL} / 6$ (Charles River) mouse muscles was performed by $\mathrm{BaCl}_{2}$ injection in the TA muscle of 8-week old mice, under zolazepam/tiletamine anaesthesia ${ }^{59}$. These animal studies were approved by the San Raffaele University Animal Care Committee.

RNA electromobility shift assays. The $H M G B 1 \mathrm{cRNA}$ probes were produced by in vitro transcription using a T7 RNA polymerase ${ }^{60}$. All $H M G B 1$ probes $\left(5^{\prime} \mathrm{UTR}\right.$ and P1 to P12) were generated by PCR amplification using a forward primer fused to the T7 promoter as well as PCMV-HMGB1 expression vector as the template (see Supplementary Table S4). For smaller probes (P4-1 to P4-3), oligonucleotide sense and anti-sense were directly annealed and used for in vitro transcription. The RNA-binding assays were performed ${ }^{22}$ by incubating either $10 \mu \mathrm{g}$ total cell extracts 
or $300 \mathrm{ng}$ purified recombinant protein (GST or GST-HuR) with 50,000 c.p.m. of ${ }^{32} \mathrm{P}$-labelled cRNAs in a total volume of $20 \mu \mathrm{l}$ EBMK buffer $(25 \mathrm{mM}$ HEPES $\mathrm{pH}$ 7.6, $1.5 \mathrm{mM} \mathrm{KCl}, 5 \mathrm{mM} \mathrm{MgCl}_{2}, 75 \mathrm{mM} \mathrm{NaCl}, 6 \%$ sucrose and protease inhibitors) at RT for $15 \mathrm{~min}$. For competition assays, $0.01 \times, 0.1 \times, 1 \times, 10 \times$ and $100 \times$ excess unlabelled specific or unspecific transcripts were incubated with the TCE for $15 \mathrm{~min}$ at RT before the ${ }^{32} \mathrm{P}$-labelled probes were added to the reaction. Two microlitres $\mu \mathrm{l}$ of a $50 \mathrm{mg} \mathrm{ml}^{-1}$ heparin sulphate stock solution was then added to the reaction for an additional $15 \mathrm{~min}$ at RT. In supershift experiments, $5 \mu \mathrm{g}$ of a purified monoclonal anti-HuR antibody was then added to the reaction for an additional $15 \mathrm{~min}$ at RT. Samples were then loaded on a $4 \%$ polyacrylamide gel containing $0.05 \% \mathrm{NP}-40$.

Quantitative RT-PCR. One microgram of total RNA was reverse transcribed using the M-MuLV Reverse Transcriptase (New England Biolabs) according to the manufacturer's protocol. A total of 1/80 dilution of cDNA was used to detect $H M G B 1, G A P D H$ and $R l u c$ mRNAs using SsoFast EvaGreen Supermix (Bio-Rad). Expression of $H M G B 1$ and $R$ luc was standardized using GAPDH as a reference, and relative levels of expression were quantified by calculating $2-\Delta \Delta \mathrm{C}_{\mathrm{T}}$, where $\Delta \Delta \mathrm{C}_{\mathrm{T}}$ is the difference in CT between target and reference.

For miRNA detection, $200 \mathrm{ng}$ of total RNA was reverse transcribed using the Universal cDNA synthesis kit (Exiqon) and the presence of miR-1192, miR-16 and U6 was assessed by qPCR using the SyBr Green Master Mix (Exiqon).

Northern blot analysis and Actinomycin D pulse-chase experiments. The extraction of total RNA was performed using Trizol reagent (Invitrogen) ${ }^{22}$. For the isolation of miRNAs, twice as much isopropanol was used in the RNA purification protocol. Northern blot analysis was performed using $10 \mu \mathrm{g}$ total RNA ${ }^{22}$. After transferring to a Hybond-N membrane (Amersham) and UV-cross-linking, the blot was hybridized with probes specific for $M y o D^{17}, G A P D H^{17}, 18 S^{61}, 5.8 S^{34}$ and HMGB1 mRNAs were generated using the PCR Purification Kit (GE Healthcare) with primers described below. The probes were radiolabelled with $\alpha-{ }^{32} \mathrm{P}$ dCTP using Ready-to-Go DNA labelling beads (GE Healthcare) according to the manufacturer's instructions. The stability of $H M G B 1$ mRNA was assessed by the addition of the general transcriptional inhibitor actinomycin $\mathrm{D}\left(5 \mu \mathrm{g} \mathrm{ml}{ }^{-1}\right)^{61}$ for the indicated periods of time. Total RNA was isolated from the cells after $0,4,6,8$, 10 and $12 \mathrm{~h}$ following ActD treatment using TRIzol reagent (Invitrogen), and analysed by northern blotting. Full blots are provided in Supplementary Fig S12.

For miRNA detection, $25 \mu \mathrm{g}$ of total RNA was separated on a $12 \%$ denaturing urea polyacrylamide gel. RNA was subsequently transferred to a Hybond- ${ }^{+}$ membrane (Amersham Biosciences) and cross-linked to the membrane. Hybridization was carried out by using ULTRAHybOligo solution according to the manufacturer's instructions (Ambion). The probe sequences were complementary to the mature forms of miR-16 or U6 RNA and were labelled using StarFire system (Integrated DNA Technologies) according to the manufacturer's protocol.

Polysome fractionation. Forty million myoblasts were grown and treated with small interfering RNAs as described above and polysome fractionation experiments were performed. Briefly, the cytoplasmic extracts obtained from lysed myoblast cells were centrifuged at $130000 \mathrm{~g}$ for $2 \mathrm{~h}$ on a sucrose gradient $(10-50 \% \mathrm{w} / \mathrm{v})^{62,63}$. Polysomal (P) or non-polysomal (NP) fractions were pooled and RNA was extracted using Trizol LS (Invitrogen). RNA samples were then analysed on an agarose gel. The levels of $H M G B 1$ and GAPDH mRNAs were determined using quantitative RT-PCR.

Luciferase activity. The activity of $R$ Luc was measured using a Renilla luciferase assay system (Promega) with a luminometer following the manufacturer's instructions.

Fluorescence in situ hybridization. The fluorescence in situ hybridization experiments were performed ${ }^{29}$ using a DNA fragment of $\sim 500 \mathrm{bp}$ corresponding to the coding region of mouse HMGB1. The fragment was amplified by PCR using the following primers fused to either a $\mathrm{T} 7$ or T3 minimal promoter sequence: HMGB1 forward, $5^{\prime}$-AAA AAG CCG AGA GGC AAA AT- ${ }^{\prime}$, and HMGB1 reverse, $5^{\prime}$-CTT TTT CGC TGC ATC AGG TT- $3^{\prime}$. The PCR product was used as the template for in vitro transcription of the HMGB1 probe needed for fluorescence in situ hybridization. The anti-sense (T3) and sense (T7) probes were prepared using digoxigenin-RNA labelling mix from Roche Diagnostics. The RNA probes were quantified, denatured and incubated with permeabilized cells at $37^{\circ} \mathrm{C}$ overnight in the hybridization buffer ( $50 \%$ formamide, $5 \times$ SSC, $50 \mathrm{mM}$ phosphate buffer, $\mathrm{pH}=7.4,5 \times$ Denhardt's, $1 \mathrm{mM}$ EDTA and $250 \mathrm{ng} \mathrm{\mu l}^{-1}$ of salmon sperm DNA). After the hybridization, the cells were used for IF to detect the HMGB1 mRNA and HuR protein ${ }^{29}$. Finally, the cells were incubated with secondary goat anti-rabbit antibody and anti-DIG antibody for IF.

Preparation of mRNA complexes and analysis with RT-PCR. TCE were prepared in lysis buffer (50 mM Tris, pH 8; 0.5\% Triton X-100; $150 \mathrm{mM} \mathrm{NaCl}$; complete protease inhibitor from Roche). Twenty-five microlitres of the anti-HuR
(3A2) or IgG (Jackson Immunoresearch Laboratories) antibodies were incubated with $200 \mu \mathrm{l}$ of pre-swelled protein A-Sepharose beads for $4 \mathrm{~h}$ at $4{ }^{\circ} \mathrm{C}$. Alternatively, $\mathrm{C} 2 \mathrm{C} 12$ cells depleted or not of HuR were incubated with an anti-Ago2 (Cell Signalling) or IgG control antibody. After three washes in lysis buffer, $1.5 \mathrm{mg}$ of cell extract was added overnight at $4{ }^{\circ} \mathrm{C}$. The final dilution of the antibodies during the incubation with lysates is $1 / 18$. Beads were washed three times with cell lysis buffer, incubated with proteinase $\mathrm{K}$ and the RNA isolated by phenol/chloroform extraction followed by precipitation overnight at $-20^{\circ} \mathrm{C}$ with isopropanol ${ }^{17,64}$. Purified RNA was resuspended in $12 \mu \mathrm{l}$ of water, and $2 \mu \mathrm{l}$ was reverse transcribed using the M-MuLV Reverse Transcriptase (New England Biolabs) according to the manufacturer's protocol. Association of HMGB1 and $\beta$-actin mRNAs with HuR as well as HMGB1 with Ago2 was defined using quantitative RT-PCR. Ten microlitres of purified RNA was reverse transcribed using the Universal cDNA synthesis kit (Exiqon) and the presence of miR-1192, miR-16 and U6 was assessed by qPCR.

cDNA array analysis. Microarray experiments were performed using mouse array, which contain 17,000 probe sets of known and unknown expressed sequence $\operatorname{tags}^{65}$. HuR was immunoprecipitated from exponentially growing $\mathrm{C} 2 \mathrm{C} 12$ cells using an anti-HuR monoclonal antibody (3A2) and an anti-IgG monoclonal antibody as a negative control. The final dilution of the antibodies during the overnight incubation with lysates is $1 / 18$. Then the samples were spun 5 min at$3,000 \mathrm{~g}$ and washed with TSE1 (0.1\% SDS, $1 \%$ Triton X-100, $2 \mathrm{mM}$ EDTA, $20 \mathrm{mM}$ Tris-HCl pH: 8.1, $150 \mathrm{mM} \mathrm{NaCl})$, TSE2 (0.1\% SDS, $1 \%$ Triton X-100, $2 \mathrm{mM}$ EDTA, $20 \mathrm{mM}$ Tris- $\mathrm{HCl} \mathrm{pH:} \mathrm{8.1,500} \mathrm{mM} \mathrm{NaCl})$ and TSE3 $(0.25 \mathrm{M}, \mathrm{LiCl}, 1 \% \mathrm{NP}-$ 40, $1 \%$ deoxycholate, $1 \mathrm{mM}$ EDTA, $10 \mathrm{mM}$ Tris- $\mathrm{HCl} \mathrm{pH}: 8.1$ ) buffers. The immunoprecipitate were then incubated for $30 \mathrm{~min}$ at $55^{\circ} \mathrm{C}$ in $100 \mathrm{ml} \mathrm{NT2}$ buffer (50 mM Tris pH:7.4, $150 \mathrm{mM} \mathrm{NaCl}, 1 \mathrm{mM} \mathrm{MgCl} 2,0.05 \% \mathrm{NP}-40$ ) with0.1\% SDS and $30 \mathrm{mg}$ proteinase $\mathrm{K}$. The associated RNAs were extracted by adding $\sim 15 \mathrm{ml}$ of $2 \mathrm{M} \mathrm{NaOAc} p H: 4.0,150 \mu \mathrm{l}$ of water saturated phenol and $\sim 30 \mu \mathrm{l}$ chloroform followed by $15 \mathrm{~min}$ incubation on ice. After spinning $(12,000 \mathrm{~g}$ for $20 \mathrm{~min})$ the aqueous phase is mixed with glycogen and isopropanol and incubated overnight at $-20^{\circ} \mathrm{C}$. The isolated RNAs were then resuspended in water and hybridized on cDNA arrays. The data were processed using the Array Pro software (Media Cybernetics), then normalized by $Z$-score transformation ${ }^{66}$ and used to calculate differences in signal intensities. Significant values were tested using a two-tailed $Z$ test and a $P$ of $\leq 0.01$. The data were calculated from two independent experiments.

Subcellular fractionation. Subcellular fractionation was performed using the PARIS kit (Ambion) (Austin, TX) according the manufacturer's instructions. An equal number of cells per sample were used.

Biotin pull-down assay. The P4 fragment of the $3^{\prime}$ UTR of mouse HMGB1 was subcloned into a pGEM-Teasy vector (Promega) according to the manufacturer's instructions by performing PCR amplification using the following primers: forward $5^{\prime}$-GCC ACT AAC CTT GCC TGG TA- $3^{\prime}$ and reverse $5^{\prime}$-TCG TAT AAG CTG CAT CAG AGA CA- $3^{\prime}$. The transcript is transcribed using the T7RiboMAX Express large scale RNA production system (Promega) according to the manufacturer's instructions using the NotI digested PGEM-Teasy-P3P4 vector as a template. For preparing protein extracts, $30-40$ millions of cells were washed with ice-cold PBS and resuspended in $1 \mathrm{ml}$ of EBMK buffer ( $25 \mathrm{mM}$ Hepes $\mathrm{pH} 7,6$; $5 \mathrm{mM} \mathrm{MgCl} ; 1,5 \mathrm{mM} \mathrm{KCl} ; 75 \mathrm{mM} \mathrm{NaCl} ; 175 \mathrm{mM}$ sucrose) containing 0,5\% NP-40, complete protease inhibitor without EDTA (Roche). Lysates were sonicated for $10 \mathrm{~s}$ 3 times at $200 \mathrm{~W}$ and cleared by centrifugation at $12,000 \mathrm{~g}$ for $15 \mathrm{~min}$. The protein concentration was determined (Bio-Rad microassay) and $1 \mathrm{mg}$ were used for each assay. Biotin pull-down assay is performed using Miltenyi Biotech mMACS streptavidin kit according to the manufacturer's instructions.

Primers used to prepare probes for northern blot analysis. mHMGB1: For: $5^{\prime}-$ GCA TCC TGG CTT ATC CAT TG-3'; rev: 5'-TGC TCT TTT CAG CCT TGA CC- $3^{\prime}$

mGAPDH: For: 5'-AAG GTC ATC CCA GAG CTG AA-3'; rev: 5'-AGG AGA CAA CCT GGT CCT CA-3'

Statistical analyses. The statistical analyses in this study were performed using the Graphpad Prism5 software to determine significance (two-tailed, Student's $t$ test).

\section{References}

1. Charge, S. B. \& Rudnicki, M. A. Cellular and molecular regulation of muscle regeneration. Physiol. Rev. 84, 209-238 (2004).

2. Zhang, K., Sha, J. \& Harter, M. L. Activation of Cdc6 by MyoD is associated with the expansion of quiescent myogenic satellite cells. J. Cell Biol. 188, 39-48 (2010).

3. De Mori, R. et al. Multiple effects of high mobility group box protein 1 in skeletal muscle regeneration. Arterioscler. Thromb. Vasc. Biol. 27, 2377-2383 (2007). 
4. Filippin, L. I., Moreira, A. J., Marroni, N. P. \& Xavier, R. M. Nitric oxide and repair of skeletal muscle injury. Nitric Oxide 21, 157-163 (2009).

5. Palumbo, R. et al. Extracellular HMGB1, a signal of tissue damage, induces mesoangioblast migration and proliferation. J. Cell Biol. 164, 441-449 (2004).

6. Takaesu, G. et al. Activation of p38alpha/beta MAPK in myogenesis via binding of the scaffold protein JLP to the cell surface protein Cdo. J. Cell Biol. 175, 383-388 (2006).

7. Serra, C. et al. Functional interdependence at the chromatin level between the MKK6/p38 and IGF1/PI3K/AKT pathways during muscle differentiation. Mol. Cell 28, 200-213 (2007).

8. Jones, N. C. et al. The p38alpha/beta MAPK functions as a molecular switch to activate the quiescent satellite cell. J. Cell Biol. 169, 105-116 (2005).

9. Sorci, G., Riuzzi, F., Arcuri, C., Giambanco, I. \& Donato, R. Amphoterin stimulates myogenesis and counteracts the antimyogenic factors basic fibroblast growth factor and S100B via RAGE binding. Mol. Cell Biol. 24, 4880-4894 (2004).

10. Riuzzi, F., Sorci, G. \& Donato, R. RAGE expression in rhabdomyosarcoma cells results in myogenic differentiation and reduced proliferation, migration, invasiveness, and tumor growth. Am. J. Pathol. 171, 947-961 (2007).

11. Riuzzi, F., Sorci, G. \& Donato, R. S100B stimulates myoblast proliferation and inhibits myoblast differentiation by independently stimulating ERK1/2 and inhibiting p38 MAPK. J. Cell Physiol. 207, 461-470 (2006).

12. Riuzzi, F., Sorci, G., Sagheddu, R. \& Donato, R. HMGB1-RAGE regulates muscle satellite cell homeostasis through p38-MAPK- and myogenindependent repression of Pax7 transcription. J. Cell Sci. 125, 1440-1454 (2012).

13. Begum, N., Pash, J. M. \& Bhorjee, J. S. Expression and synthesis of high mobility group chromosomal proteins in different rat skeletal cell lines during myogenesis. J Biol Chem 265, 11936-11941 (1990).

14. Abdelmohsen, K., Kuwano, Y., Kim, H. H. \& Gorospe, M. Posttranscriptional gene regulation by RNA-binding proteins during oxidative stress: implications for cellular senescence. Biol. Chem. 389, 243-255 (2008).

15. von Roretz, C. \& Gallouzi, I. E. Decoding ARE-mediated decay: is microRNA part of the equation? J. Cell Biol. 181, 189-194 (2008).

16. Figueroa, A. et al. Role of HuR in skeletal myogenesis through coordinate regulation of muscle differentiation genes. Mol. Cell Biol. 23, 4991-5004 (2003).

17. van der Giessen, K., Di-Marco, S., Clair, E. \& Gallouzi, I. E. RNAi-mediated HuR depletion leads to the inhibition of muscle cell differentiation. J. Biol. Chem. 278, 47119-47128 (2003).

18. von Roretz, C., Beauchamp, P., Di Marco, S. \& Gallouzi, I. E. HuR and myogenesis: being in the right place at the right time. Biochim. Biophys. Acta. 1813, 1663-1667 (2011).

19. Yaffe, D. \& Saxel, O. Serial passaging and differentiation of myogenic cells isolated from dystrophic mouse muscle. Nature 270, 725-727 (1977).

20. Conejo, R., de Alvaro, C., Benito, M., Cuadrado, A. \& Lorenzo, M. Insulin restores differentiation of Ras-transformed C2C12 myoblasts by inducing NFkappaB through an AKT/P70S6K/p38-MAPK pathway. Oncogene 21, 3739-3753 (2002).

21. Li, X. L., Andersen, J. B., Ezelle, H. J., Wilson, G. M. \& Hassel, B. A. Posttranscriptional regulation of RNase- $\mathrm{L}$ expression is mediated by the 3'untranslated region of its mRNA. J. Biol. Chem. 282, 7950-7960 (2007)

22. Dormoy-Raclet, V. et al. The RNA-binding protein HuR promotes cell migration and cell invasion by stabilizing the beta-actin mRNA in a U-richelement-dependent manner. Mol. Cell Biol. 27, 5365-5380 (2007).

23. Buckingham, M. et al. The formation of skeletal muscle: from somite to limb. J. Anat. 202, 59-68 (2003).

24. Calogero, S. et al. The lack of chromosomal protein Hmg1 does not disrupt cell growth but causes lethal hypoglycaemia in newborn mice. Nat. Genet. 22, 276-280 (1999).

25. Kelly, R., Alonso, S., Tajbakhsh, S., Cossu, G. \& Buckingham, M. Myosin light chain $3 \mathrm{~F}$ regulatory sequences confer regionalized cardiac and skeletal muscle expression in transgenic mice. J. Cell Biol. 129, 383-396 (1995).

26. Cossu, G. et al. Activation of different myogenic pathways: myf-5 is induced by the neural tube and MyoD by the dorsal ectoderm in mouse paraxial mesoderm. Development 122, 429-437 (1996)

27. Riuzzi, F., Sorci, G., Beccafico, S. \& Donato, R. S100B engages RAGE or bFGF/ FGFR1 in myoblasts depending on its own concentration and myoblast density. Implications for muscle regeneration. PloS One 7, e28700 (2012).

28. Gallouzi, I. E. \& Steitz, J. A. Delineation of mRNA export pathways by the use of cell-permeable peptides. Science 294, 1895-1901 (2001).

29. Lian, X. J. \& Gallouzi, I. E. Oxidative stress increases the number of stress granules in senescent cells and triggers a rapid decrease in p21wafl/cip1 translation. J. Biol Chem. 284, 8877-8887 (2009).

30. Beauchamp, P. et al. The cleavage of HuR interferes with its transportin-2 mediated nuclear import and promotes muscle fiber formation. Cell Death Differ. 17, 1588-1599 (2010).

31. Lee, J. E., Lee, J. Y., Wilusz, J., Tian, B. \& Wilusz, C. J. Systematic analysis of ciselements in unstable mRNAs demonstrates that CUGBP1 is a key regulator of mRNA decay in muscle cells. PloS One 5, e11201 (2010).
32. Kim, H. H. et al. HuR recruits let-7/RISC to repress c-Myc expression. Genes Dev. 23, 1743-1748 (2009).

33. Bhattacharyya, S. N., Habermacher, R., Martine, U., Closs, E. I. \& Filipowicz, W. Relief of microRNA-mediated translational repression in human cells subjected to stress. Cell 125, 1111-1124 (2006).

34. Dormoy-Raclet, V., Markovits, J., Jacquemin-Sablon, A. \& Jacquemin-Sablon, $\mathrm{H}$. Regulation of Unr expression by 5'- and 3'-untranslated regions of its mRNA through modulation of stability and IRES mediated translation. RNA. Biol. 2, e27-e35 (2005).

35. Bordeleau, M. E. et al. RNA-mediated sequestration of the RNA helicase eIF4A by Pateamine A inhibits translation initiation. Chem. Biol. 13, 1287-1295 (2006).

36. Dang, Y. et al. Eukaryotic initiation factor 2alpha-independent pathway of stress granule induction by the natural product pateamine A. J. Biol. Chem. 281, 32870-32878 (2006).

37. Hood, K. A., West, L. M., Northcote, P. T., Berridge, M. V. \& Miller, J. H. Induction of apoptosis by the marine sponge (Mycale) metabolites, mycalamide A and pateamine. Apoptosis. 6, 207-219 (2001).

38. Fabian, M. R., Sonenberg, N. \& Filipowicz, W. Regulation of mRNA translation and stability by microRNAs. Annu. Rev. Biochem. 79, 351-379 (2010).

39. $\mathrm{Xu}, \mathrm{F}$. et al. Loss of repression of HuR translation by miR-16 may be responsible for the elevation of HuR in human breast carcinoma. J. Cell Biochem. 111, 727-734 (2010).

40. Abdelmohsen, K., Srikantan, S., Kuwano, Y. \& Gorospe, M. miR-519 reduces cell proliferation by lowering RNA-binding protein HuR levels. Proc. Natl Acad. Sci. USA 105, 20297-20302 (2008).

41. Marasa, B. S. et al. MicroRNA profiling in human diploid fibroblasts uncovers miR-519 role in replicative senescence. Aging (Albany NY) 2, 333-343 (2010).

42. van der Giessen, K. \& Gallouzi, I. E. Involvement of transportin 2-mediated HuR import in muscle cell differentiation. Mol. Biol. Cell 18, 2619-2629 (2007).

43. Ferrari, S., Finelli, P., Rocchi, M. \& Bianchi, M. E. The active gene that encodes human high mobility group 1 protein (HMG1) contains introns and maps to chromosome 13. Genomics 35, 367-371 (1996).

44. Ferrari, S., Ronfani, L., Calogero, S. \& Bianchi, M. E. The mouse gene coding for high mobility group 1 protein (HMG1). J. Biol. Chem. 269, 28803-28808 (1994).

45. Bustin, M. Regulation of DNA-dependent activities by the functional motifs of the high-mobility-group chromosomal proteins. Mol. Cell Biol. 19, 5237-5246 (1999).

46. Chiang, H. R. et al. Mammalian microRNAs: experimental evaluation of novel and previously annotated genes. Genes Dev 24, 992-1009 (2010).

47. Kuchen, S. et al. Regulation of microRNA expression and abundance during lymphopoiesis. Immunity 32, 828-839 (2010).

48. Linsen, S. E. et al. Limitations and possibilities of small RNA digital gene expression profiling. Nat. Methods 6, 474-476 (2009).

49. Ozsolak, F. \& Milos, P. M. RNA sequencing: advances, challenges and opportunities. Nat. Rev. Genet. 12, 87-98 (2011).

50. Chi, S. W., Zang, J. B., Mele, A. \& Darnell, R. B. Argonaute HITS-CLIP decodes microRNA-mRNA interaction maps. Nature 460, 479-486 (2009).

51. Kundu, P., Fabian, M. R., Sonenberg, N., Bhattacharyya, S. N. \& Filipowicz, W HuR protein attenuates miRNA-mediated repression by promoting miRISC dissociation from the target RNA. Nucleic Acid Res. 40, 5088-5100 (2012).

52. Kedde, M. et al. RNA-binding protein Dnd1 inhibits microRNA access to target mRNA. Cell 131, 1273-1286 (2007).

53. Andersson, U. \& Tracey, K. J. HMGB1 Is a Therapeutic Target for Sterile Inflammation and Infection. Annu. Rev. Immunol. 29, 139-162 (2010).

54. Bianchi, M. E. DAMPs, PAMPs and alarmins: all we need to know about danger. J. Leukoc. Biol. 81, 1-5 (2007).

55. Scaffidi, P., Misteli, T. \& Bianchi, M. E. Release of chromatin protein HMGB1 by necrotic cells triggers inflammation. Nature 418, 191-195 (2002).

56. Bianchi, M. E. \& Manfredi, A. A. High-mobility group box 1 (HMGB1) protein at the crossroads between innate and adaptive immunity. Immunol. Rev. 220, 35-46 (2007).

57. Gallouzi, I. E. et al. HuR binding to cytoplasmic mRNA is perturbed by heat shock. Proc. Natl Acad. Sci. USA 97, 3073-3078 (2000).

58. Cossu, G., Tajbakhsh, S. \& Buckingham, M. How is myogenesis initiated in the embryo? Trends. Genet. 12, 218-223 (1996).

59. Caldwell, C. J., Mattey, D. L. \& Weller, R. O. Role of the basement membrane in the regeneration of skeletal muscle. Neuropathol. Appl. Neurobiol. 16, 225-238 (1990).

60. Gallouzi, I. E. et al. A novel phosphorylation-dependent RNase activity of GAP-SH3 binding protein: a potential link between signal transduction and RNA stability. Mol. Cell. Biol. 18, 3956-3965 (1998).

61. Di Marco, S. et al. NF-(kappa)B-mediated MyoD decay during muscle wasting requires nitric oxide synthase mRNA stabilization, HuR protein, and nitric oxide release. Mol. Cell. Biol. 25, 6533-6545 (2005). 
62. Cammas, A. et al. Cytoplasmic relocalization of heterogeneous nuclear ribonucleoprotein A1 controls translation initiation of specific mRNAs. Mol. Biol. Cell. 18, 5048-5059 (2007).

63. Di Marco, S. et al. The translation inhibitor pateamine A prevents cachexiainduced muscle wasting in mice. Nat. Commun. 3, 896 (2012).

64. Tenenbaum, S. A., Lager, P. J., Carson, C. C. \& Keene, J. D. Ribonomics: identifying mRNA subsets in mRNP complexes using antibodies to RNAbinding proteins and genomic arrays. Methods. 26, 191-198 (2002).

65. Cheadle, C., Vawter, M. P., Freed, W. J. \& Becker, K. G. Analysis of microarray data using Z score transformation. J. Mol. Diagn. 5, 73-81 (2003).

66. Lopez de Silanes, I. et al. Identification and functional outcome of mRNAs associated with RNA-binding protein TIA-1. Mol. Cell Biol. 25, 9520-9531 (2005).

\section{Acknowledgements}

We offer our sincere thanks to Dr C. von Roretz for critical review of this manuscript and insightful discussion. We wish to thank Heikki Rauvala (Helsinki, Finland) for providing recombinant HMGB1. VDR is a Research Fellow of the Terry Fox foundation through an award from the Canadian Cancer Society (former National Cancer Institute of Canada). This work was supported by a CIHR (MOP-89798) operating grant and a NSERC discovery grant (RGPIN/371668-200) to I.G, a EU FP7 grant (Endostem) to M.E.B. and S.B. I.G. is a recipient of a TierII Canada Research Chair.

\section{Author contributions}

V.D. and A.C. designed, carried out, analysed and interpreted all of the in vitro experiments in the manuscript. B.C., S.B. and M.B. designed and carried out the in vivo experiments described in Figs 2 and 3. X.J.L., K.V. and M.Z. assisted with some of the in vitro experiments. F.R., G.S. and R.D. designed and carried out the experiments described in Supplementary Fig. S2c,d as well as Supplementary Fig. S10. R.D. helped writing part of the manuscript. B.W. provided technical expertise and helped in the analysis of microarray and sequencing experiments. S.D. helped in the design of several experiments in the manuscript. M.B. participated in writing and editing the manuscript. I.E.G. conceived and helped design all experiments in the manuscript, aided in the analysis of the data and wrote the manuscript.

\section{Additional information}

Accession codes: Microarray data have been deposited in Gene Expression Omnibus under accession code GSE49857.

Supplementary Information accompanies this paper at http://www.nature.com/ naturecommunications

Competing financial interests: M.E.B. is part owner of HMGBiotech, a company that provides reagents and services for HMGB1 research. The remaining authors declare no competing financial interests.

Reprints and permission information is available online at http://npg.nature.com/ reprintsandpermissions/

How to cite this article: Dormoy-Raclet, V. et al. HuR and miR-1192 regulate myogenesis by modulating the translation of HMGB1 mRNA. Nat. Commun. 4:2388 doi: $10.1038 /$ ncomms3388 (2013). 